\title{
Investigation of liver alcohol dehydrogenase catalysis using an NADH biomimetic and comparison with a synthetic zinc model complex
}

\author{
James R. Sunderland \\ Xingjian Tao \\ Elizabeth E. Butrick \\ Lauren C, Keilich

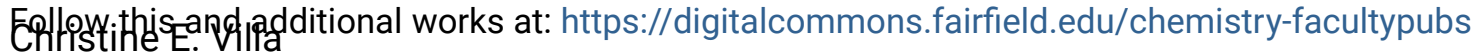 \\ Copyright 2016 Elsevier
}

The author post-print has been archived here with permission from the copyright holder. See next page for additional authors

Peer Reviewed

\section{Repository Citation}

Sunderland, James R.; Tao, Xingjian; Butrick, Elizabeth E.; Keilich, Lauren C,; Villa, Christine E.; Miecznikowski, John R.; and Jain, Swapan S., "Investigation of liver alcohol dehydrogenase catalysis using an NADH biomimetic and comparison with a synthetic zinc model complex" (2016). Chemistry \& Biochemistry Faculty Publications. 42.

https://digitalcommons.fairfield.edu/chemistry-facultypubs/42

\section{Published Citation}

Sunderland, J. R., Tao, X., Butrick, E. E., Keilich, L. C., Villa, C. E., Miecznikowski, J. R., \& Jain, S. S. (2016). Investigation of liver alcohol dehydrogenase catalysis using an NADH biomimetic and comparison with a synthetic zinc model complex. Polyhedron, 114, 145-151. https://doi.org/10.1016/j.poly.2015.11.027.

This item has been accepted for inclusion in DigitalCommons@Fairfield by an authorized administrator of DigitalCommons@Fairfield. It is brought to you by DigitalCommons@Fairfield with permission from the rightsholder(s) and is protected by copyright and/or related rights. You are free to use this item in any way that is permitted by the copyright and related rights legislation that applies to your use. For other uses, you need to obtain permission from the rights-holder(s) directly, unless additional rights are indicated by a Creative Commons license in the record and/or on the work itself. For more information, please contact digitalcommons@fairfield.edu. 


\section{Authors}

James R. Sunderland; Xingjian Tao; Elizabeth E. Butrick; Lauren C, Keilich; Christine E. Villa; John R. Miecznikowski; and Swapan S. Jain 


\title{
Investigation of liver alcohol dehydrogenase catalysis using an NADH biomimetic and comparison with a synthetic zinc model complex
}

\author{
James R. Sunderland ${ }^{1}$, Xingjian Tao ${ }^{1}$, Elizabeth E. Butrick ${ }^{2}$, Lauren C. Keilich ${ }^{2}$, \\ Christine E. Villa ${ }^{2}$, John R. Miecznikowski2 ${ }^{*}$, and Swapan S. Jain ${ }^{*}$ \\ ${ }^{1}$ Department of Chemistry, Bard College, 30 Campus Road, Annandale-on-Hudson, NY 12504, USA \\ ${ }^{2}$ Department of Chemistry and Biochemistry, Fairfield University, 1073 North Benson Road, Fairfield, CT \\ 06824, USA \\ *Corresponding Authors: Tel: +1845752 2354. Fax: +1 845752 2339. Email: sjain@bard.edu \\ * Tel: 1-203-254-4000 x 2125. Fax: +1-203-254-4034. Email: jmiecznikowski@fairfield.edu
}

\begin{abstract}
We have compared the catalytic activity of horse liver alcohol dehydrogenase (LADH) with a synthetic zinc model complex in the presence of N-benzyl-1,4dihydronicotinamide (BNAH), a cofactor which serves as a biomimetic for the natural cofactor NADH. We have used five different substrates (benzaldehyde, p-anisaldehyde, 4-nitrobenzaldhyde, 2-pyridine carboxaldehyde, and 5-pyrimidine carboxaldehyde) in this study. These substrates vary in their substituent inductive effect, which is the ability to donate or withdraw electron density away from their carbonyl-functional group. Our results reveal that in the presence of $\mathrm{NADH}$, geometric factors (induced fit of the substrate and cofactor in the enzyme active site) are vital. However, reactivity assays show that in the presence of $\mathrm{BNAH}$, there is a strong correlation between substrate electronic environment and the observed catalytic rate, i.e. the more electron withdrawn the substrate, the greater the speed at which the reduction reaction occurs. NMR spectroscopy reveals that a synthetic zinc model complex catalyzes the reduction of substrates in a manner consistent with LADH enzyme.
\end{abstract}

Jain et al. 


\section{Introduction}

Liver alcohol dehydrogenase $(\mathrm{LADH})$ is a dimeric enzyme where each subunit of the enzyme contains a cofactor-binding domain and a $\mathrm{Zn}^{2+}$ metal-containing catalytic domain. [1] NADH is a natural cofactor that functions as a hydride donor in enzymatic reactions where aldehydes and ketones are reduced to their respective alcohol moieties. Binding of $\mathrm{NADH}$ occurs in close proximity to the $\mathrm{Zn}^{2+}$ center of $\mathrm{LADH}$ enzyme. [2] Crystal structure data shows that NADH binds very tightly within the coenzyme-binding domain of liver alcohol dehydrogenase enzyme by utilizing direct electrostatic contacts with eight amino acid residues. [3]

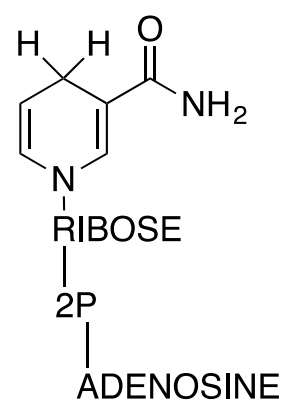

NADH

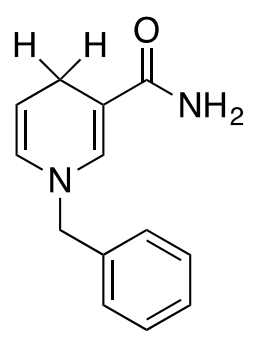

BNAH

Figure 1. Chemical structure of NADH (left) and BNAH (right).

N-benzyl-1,4-dihydronicotinamide, abbreviated as BNAH, has been used as a biomimetic in place of $\mathrm{NADH}$ for a variety of oxidoreductase enzymes including monoxygenases and dehydrogenases. [4,5] BNAH is preferred in industrial applications because unlike NADH, it does not suffer from the high cost of preparation and instability under higher temperature and pressure [6]. In 2002, Lo and Fish showed that the nicotinamide moiety is the only essential requirement for catalysis in case of horse LADH enzyme. [4] Even though the nicotinamide moiety, which is crucial for catalysis, 
is identical in case of both $\mathrm{NADH}$ and $\mathrm{BNAH}$, the chemical structure of BNAH, shown in Figure 1, lacks the ribose, pyrophosphate, and adenine groups. These substantial changes in the chemical structure of BNAH likely exclude the formation of many of the amino acid interactions that typically occur in case of bound NADH [7]. It is important to note that the missing amino acids contacts in case of BNAH binding are only responsible for cofactor binding and not catalysis.

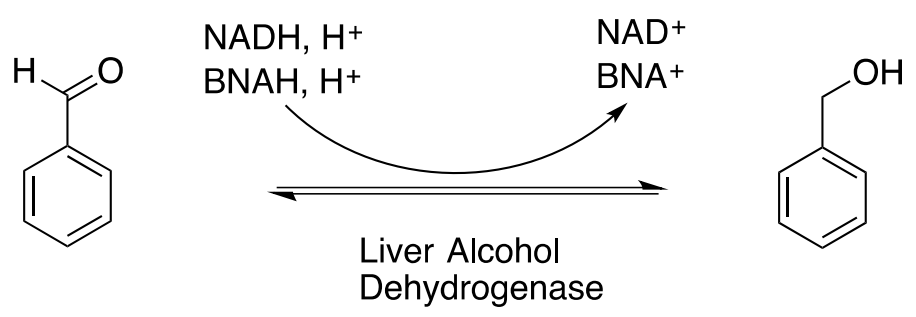

Figure 2. Reaction depicting enzymatic reduction of benzaldehyde in the presence of $\mathrm{NADH}$ cofactor. BNAH can serve as a cofactor in place of $\mathrm{NADH}$ in this reaction.

Our work compares the catalytic activity of alcohol dehydrogenase (EC 1.1.1.1), isolated from horse liver, with a synthetic model zinc complex in the presence of BNAH as a cofactor. A typical reduction reaction of benzaldehyde to benzyl alcohol is shown in Figure 2. Model enzyme complexes are synthetic complexes that mimic the active site of an enzyme in terms of chemical structure and redox properties. In case of liver alcohol dehydrogenase enzyme, the active site contains a zinc metal, which is ligated to a labile water molecule, two cysteine residues and one histidine residue (denoted as an 'SNS' ligand environment). [8] Synthetic model complexes are not only useful in industrial applications but they are also instrumental in understanding the activity and function of natural enzyme active sites. [9] Synthetic model complexes for liver alcohol dehydrogenase have been reported previously. [10-23] However, comparative analysis of 
an enzyme's catalytic rate with that of a synthetic model active site complex needs further investigation. Several structural models for LADH have been reported with the same donor atoms as the metalloenzyme, but no reactivity data were reported for these complexes. Reactivity has been reported for zinc LADH model complexes with donor atoms that are different than the enzyme's active site. [24]

We have modeled the structure and reactivity of the zinc active site using a new family of robust pincer ligands coordinating the same S,N,S donor atoms as the enzyme. $[23,25]$ We are not aware of any enzyme comparative studies where LADH enzyme is compared to the activity of LADH model complexes.

In our comparative studies of LADH enzyme with a model active site complex, we have varied the substrates of the chemical reaction. Substrates that are similar in their geometric structure but vary in their electronic properties can affect reaction rates especially those involving oxidation and reduction. The presence of electron-donating groups (EDG) or electron-withdrawing groups (EWG) can affect the enzyme's catalytic activity. [26] We have utilized a total of five substrates in our work. Their chemical structures are shown in Figure 3. We hypothesize that the reduction of an aldehyde substrate should be directly proportional to its ability to withdraw electron density away from the carbonyl carbon atom of the molecule. In comparison to benzaldehyde, panisaldehyde is expected to have a lower enzymatic rate under identical experimental conditions due to the presence of an $-\mathrm{OCH}_{3}$ substitution (EDG). Whereas 4nitrobenzaldhyde, 2-pyridine carboxaldehyde, and 5-pyrimidine carboxaldehyde are expected to accelerate the reduction reaction due to the presence of EWG groups. In previous work, Blomquist reasoned that the electron density around the carbonyl carbon 
of an aldehyde substrate should have an effect on the kinetics of the LADH enzyme catalyzed reaction. [27] It was concluded that the electron withdrawing capability of a particular substrate tends to speed up the reaction rate in small increments. It was also found that the lipophilic nature of the substrate could stabilize the protein-substrate complex more so than polarized substrates, especially during the reaction when the substrate is in an excited polarized state.

We have used UV-Vis spectroscopy and cyclic voltammetry to correlate the rates of LADH enzyme catalyzed reactions for five substrates with their substituent effect (Hammett constant) in the presence of NADH and BNAH cofactors. We have also used NMR spectroscopy to determine the reactivity of the substrates using a synthetic zinc model complex. Our work has implications about steric and electronic factors that govern chemical reactions in case of dehydrogenases. Our data shows that LADH enzyme can tolerate various substrates as well as an NADH cofactor mimic. We have shown that a synthetic zinc active site model complex catalyzes aldehyde reductions in a manner similar to LADH enzyme. 


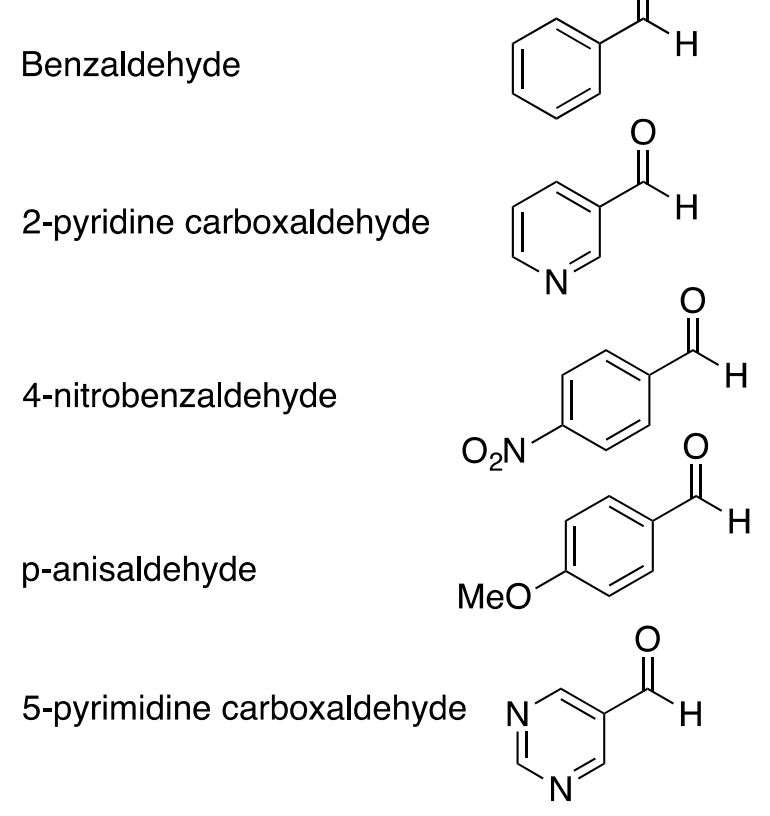

Figure 3. Chemical structures of benzaldehyde-based substrates.

\section{Experimental Section}


Synthesis of BNAH and Determination of its Extinction Coefficient

BNAH (N-benzyl-1,4-dihydronicotinamide) was synthesized and purified in our laboratory according to previously published protocols. [4] Three samples of solid BNAH (2.0 mg, $5.0 \mathrm{mg}$, and $10.0 \mathrm{mg}$ ) were weighed out and dissolved in $1.0 \mathrm{~mL}$ of acetone. Using each of these stock solutions, triplicate samples were prepared by diluting stock BNAH in $10 \mathrm{mM}$ potassium phosphate buffer, $\mathrm{pH}$ 7.10. UV-Vis spectra were recorded and the absorbance value at $360 \mathrm{~nm}$ was used to calculate the extinction coefficient (4890 $\left.\pm 75 \mathrm{~L} \cdot \mathrm{mol}^{-1} \cdot \mathrm{cm}^{-1}\right)$ of BNAH.

\section{Alcohol Dehydrogenase Enzyme Assays}

Disodium NADH salt, equine liver alcohol dehydrogenase enzyme, and the aldehyde substrates shown in Figure 3 (benzaldehyde, 4-nitrobenzaldhyde, panisaldehyde, 2-pyridine carboxaldehyde, 5-pyrimidine carboxaldehyde) were purchased from Sigma (St. Louis, MO). Enzyme and NADH stocks were prepared in potassium phosphate buffer $(10 \mathrm{mM}, \mathrm{pH} 7.10)$ and stored at $-20^{\circ} \mathrm{C}$. Aldehyde substrates were prepared in potassium phosphate buffer $(10 \mathrm{mM}, \mathrm{pH} 7.10)$ containing $1 \%$ acetone. BNAH stock was prepared in acetone and subsequently diluted with phosphate buffer containing $1 \%$ acetone. Enzyme kinetic reactions ( $2.5 \mathrm{~mL}$ final volume) were carried out in a quartz cuvette at $25^{\circ} \mathrm{C}$ in $10 \mathrm{mM}$ potassium phosphate buffer ( $\mathrm{pH}$ 7.10) with a final concentration of $150 \mu \mathrm{M}$ for each of the substrates and NADH. LADH enzyme (0.1 unit) was added directly to the cuvette containing the reaction mixture and absorbance spectra were recorded as a function of time. Change in absorbance at $340 \mathrm{~nm}$ was monitored as a function of time to determine the rate of the reaction in the presence of NADH. Reactions were carried out in triplicate. To determine the utilization of BNAH as a potential 
cofactor, identical reactions (in triplicate) were carried out except that NADH in the reaction mixture was replaced with BNAH $(150 \mu \mathrm{M})$ and absorbance change was measured at $360 \mathrm{~nm}$.

\section{Reactivity with Synthetic Model Zinc Complexes}

Model zinc complex $3 \mathrm{c}$ was synthesized in our laboratory according to previously published protocols. $[6,23,25]$ In a typical reaction, $0.1 \mathrm{mmol}$ of an aldehyde substrate, $0.2 \mathrm{mmol}$ of $\mathrm{BNAH}$, and $0.1 \mathrm{mmol}$ of the zinc complex or $0.1 \mathrm{mmol} \mathrm{ZnCl}_{2}$ were dissolved in $3 \mathrm{~mL}$ of $\mathrm{CDCl}_{3}$. The reaction was heated at reflux. Aliquots of the reaction were taken at certain times and analyzed using ${ }^{1} \mathrm{H}$ NMR spectroscopy. All data are averages of at least two runs. All of the reagents and solvents were purchased from Acros Organics except for 2-pyridine carboxaldehyde, which was purchased from Alfa Aesar.

\section{Cyclic Voltammetry}

Substrates used in the cyclic voltammetry (CV) studies were benzaldehyde, 4nitrobenzaldhyde, p-anisaldehyde, 2-pyridine carboxaldehyde, and 5-pyrimidine carboxaldehyde. The supporting electrolyte solution was $0.1 \mathrm{M}$ tertbutylammonium perchlorate prepared in acetonitrile. Substrates were dissolved at a final concentration of $2 \mathrm{mM}$ in the supporting electrolyte. CV was carried out using a gold electrode an Epsilon Potentiostat with a BASi-C-3 cell stand. Briefly, $10 \mathrm{~mL}$ of the individual substrate solution was added to the sample chamber and warmed to room temperature. The initial and final potential was set at $0 \mathrm{mV}$. The switching potential was set to $-1500 \mathrm{mV}$ with a scan rate of $50 \mathrm{mV} / \mathrm{s}$. Oxidation and reduction peaks (in $\mathrm{mV}$ ) were used to calculate Hammett constants for each substrate where benzaldehyde was used as a reference. 
Detailed calculations are shown in the supplementary information section and the data is shown as Table $\mathrm{S} 2$.

\section{Results \& Discussion}

We first determined whether the LADH enzyme under our experimental conditions could tolerate BNAH cofactor. The catalytic efficiency of LADH enzyme was measured under physiological conditions using BNAH as a biomimetic for NADH. Our work was carried out at $\mathrm{pH} 7.1$ because it has been previously shown that the association of NADH to alcohol dehydrogenase enzyme is maximal below $\mathrm{pH}$ 9. [27] The natural cofactor NADH has a UV-Vis absorption band centered at $340 \mathrm{~nm}$ whereas BNAH has a UV-Vis absorption band centered at $360 \mathrm{~nm}$ (Figure 4). In our enzyme kinetic assay, a decline in the absorbance at these wavelengths is indicative of the oxidation of the cofactor (NADH to $\mathrm{NAD}^{+}$or $\mathrm{BNAH}$ to $\mathrm{BNA}^{+}$) with the concomitant reduction of an aldehyde substrate to an alcohol. Least squares fit of the data (absorbance vs. time) was used to calculate the initial rate of the benzaldehyde reduction reaction in the presence of NADH and BNAH (inset, Figure 4). Results in Figure 4 show that LADH enzyme is able to effectively catalyze the reduction of benzaldehyde (rate of $5.0 \pm 0.3 \mathrm{nmoles} / \mathrm{min}$ ) in the presence of BNAH albeit at a lower rate in comparison to NADH $(10.5 \pm 0.3 \mathrm{nmoles} / \mathrm{min})$. It is important to note that the oxidized species $\left(\mathrm{BNA}^{+}\right)$does not absorb at $360 \mathrm{~nm}$, which allows us to monitor the enzymatic reaction progress at this particular wavelength without interference from the oxidized molecule. Enzymatic reactions tend to slow down over time due to the depletion of substrate as well as due to product inhibition. [28] In all of our reactions, we observed an initial linear increase in product formation that plateaued 
over time. Initial rate data (first 2 minutes of each reaction) as well as total product formation over a longer duration are shown in the supplementary information section (Table S1). Control reactions of $\mathrm{NADH}$ and $\mathrm{BNAH}$ with benzaldehyde alone (minus enzyme) or with enzyme alone (minus benzaldehyde) show no change in UV-Vis absorbance over a 30-minute time period (Figure S4, Supplementary Information). 

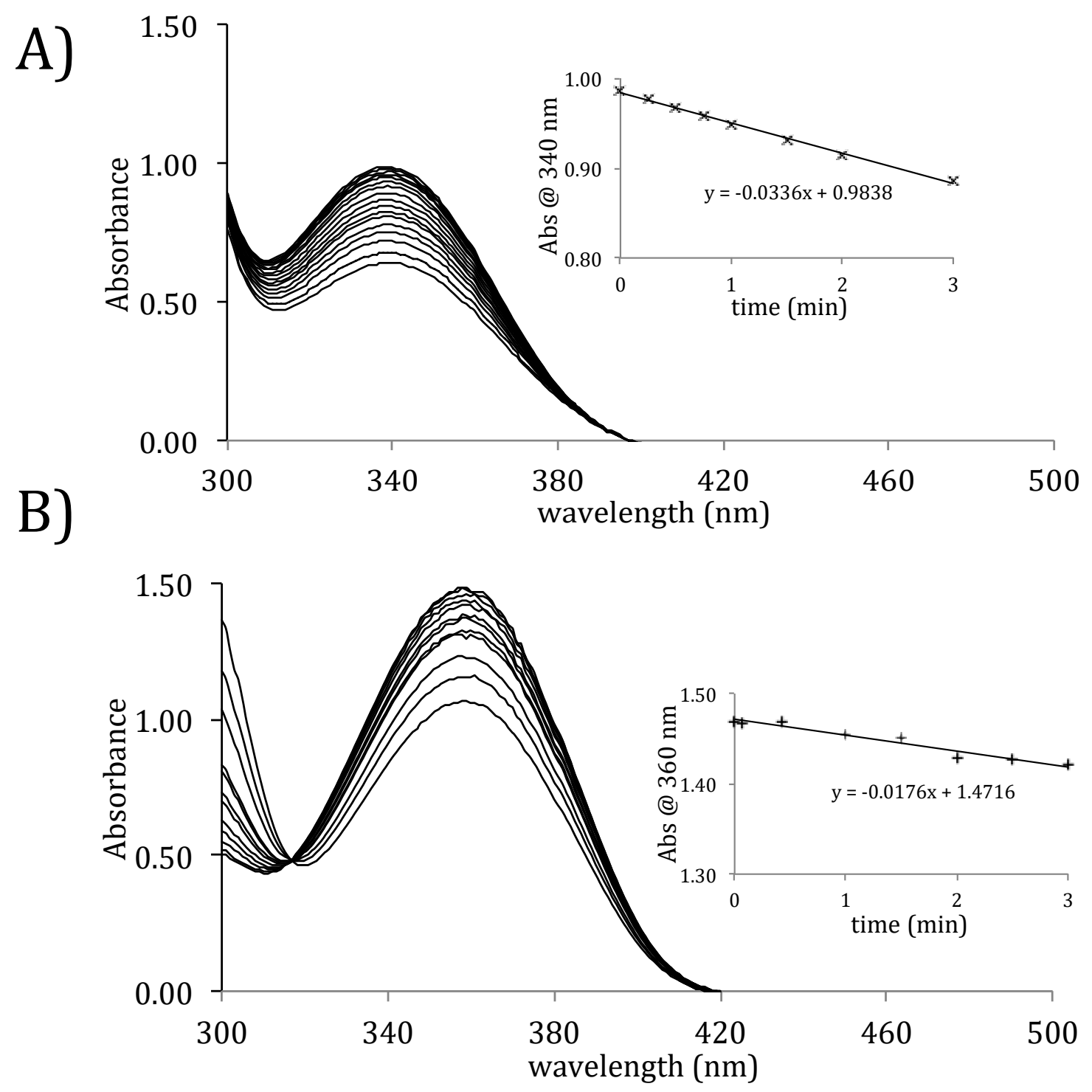

Figure 4. (a) UV-Vis spectra of the enzymatic assay with benzaldehyde substrate illustrating the depletion of (a) NADH and (b) BNAH. Insets in each graph depict the change in absorbance maximum as a function of time for each cofactor. Linear equations obtained from the least squares fitting were used to determine the initial enzymatic rate in units of nmoles/min of substrate converted to product.

The two-fold decline in the reaction rate with $\mathrm{BNAH}$, in comparison to NADH, was not unexpected as it is likely that BNAH binds weakly to the cofactor-binding domain of LADH enzyme. The low affinity binding of BNAH to the enzyme is likely a consequence 
of the significant differences in the chemical structure between NADH and BNAH. Although the chemical reaction involving the hydride transfer is the same in both cofactors, previous work has shown that $\mathrm{BNAH}\left(\mathrm{K}_{\mathrm{M}} \sim 3.7 \mathrm{mM}\right)$ binds to monooxygenase enzymes with a 130-fold lower affinity than NADH $\left(\mathrm{K}_{\mathrm{M}} \sim 27 \mu \mathrm{M}\right)$. [7] In an effort of further understand changes in reaction rates in the presence of NADH vs. BNAH, we conducted a substrate study to determine whether reactions rates are governed by the inductive effect imparted by each substrate. Hammett constants $(\sigma)$ have been widely used in inorganic, organic and biophysical studies to gauge the changes in equilibrium constant of a substrate resulting from the substitution of a hydrogen atom on the aromatic ring by other functional groups. [29] We hypothesized that the reduction rate of an aldehyde substrate should be directly proportional to its ability to withdraw electron density away from the carbonyl carbon atom of the molecule. Furthermore, the correlation between enzymatic catalytic rates and Hammett constants should be independent of the cofactor $(\mathrm{NADH}$ or $\mathrm{BNAH})$ utilized in the reaction. Cyclic voltammetry was used to measure the redox potentials for five substrates (benzaldehyde, 4-nitrobenzaldhyde, p-anisaldehyde, 2-pyridine carboxaldehyde, and 5-pyrimidine carboxaldehyde) used in this study. Cyclic voltammograms of all five substrates are presented in the supplementary information section (Figure S3).

Log $\mathrm{K}$ values were determined for each of the five substrates using redox potential data from cyclic voltammetry studies. Hammett constants have previously been reported for benzaldehyde, p-anisaldehyde, and 4-nitrobenzaldehyde. [29] In Figure 5a, log (K/Ko) values were plotted as a function of known Hammett constant values for benzaldehyde, p-anisaldehyde, and 4-nitrobenzaldehyde where $\mathrm{K}_{\mathrm{o}}$ represents the reference compound 
benzaldehyde with a $\log \left(\mathrm{K} / \mathrm{K}_{\mathrm{o}}\right)$ value of 0.0 . The data was fit to a linear least squares fit function and the equation was used to determine the unknown Hammett values for 2pyridine carboxaldehyde and 5-pyrimidine carboxaldehyde (calculations are shown in supplementary information and data is presented in Table S2). After obtaining the Hammett values for each of the substrates, we plotted initial enzymatic rates (nmoles of substrate converted to product per minute) on the y-axis with the corresponding Hammett constant values on the $\mathrm{x}$-axis (Figure $5 \mathrm{~b}$ and $5 \mathrm{c}$ ).

In case of the natural cofactor $\mathrm{NADH}$, we found a poor correlation $\left(\mathrm{R}^{2}=0.544\right)$ between the inductive effect exerted by the substrates (Hammett constant value) and their corresponding enzymatic rate (Figure 5b). This was contrary to our expectations because we hypothesized that the catalytic activity of the LADH enzyme, in the absence of major structural differences between the five substrates, should be directly proportional to the electronic environment of each substrate. Upon further reflection, reactions at the active site of an enzyme occur according to a lock-and-key mechanism where the substrates and the necessary cofactors fit in a very specific geometric position and conformation. [30] It is plausible that the NADH-bound enzyme complex only tolerates substrates with specific chemical structure and orientation. If that is the case, then the poor correlation between the substrate electronic environment and the observed catalytic rate is not surprising. Nevertheless, we observe that the three substrates (4-nitrobenzaldehyde, 2pyridine carboxaldehyde, and 5-pyrimidine carboxaldehyde) containing EWGs show a higher reaction rate whereas benzaldehyde (reference compound) and electron donating p-anisaldehyde show a lower reaction rate (Figure 5b). Even though the electronwithdrawn substrates show a higher catalytic rate, the absence of a strong correlation 
illustrates that reactions by the enzyme $\mathrm{LADH}$ in the presence of its natural cofactor NADH are primarily governed by steric and geometric factors and to a lesser extent by the inductive effect exerted by the substrate.

A)

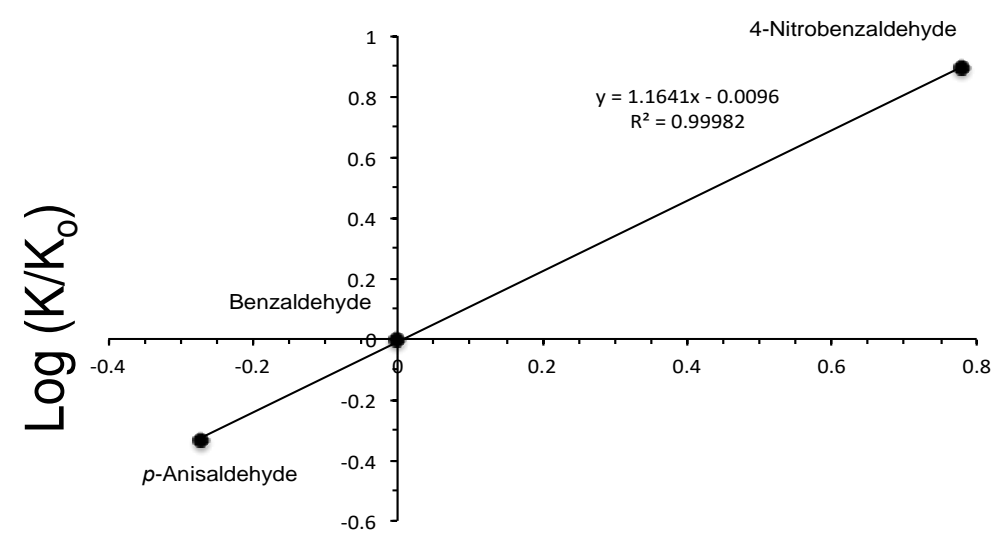

B)
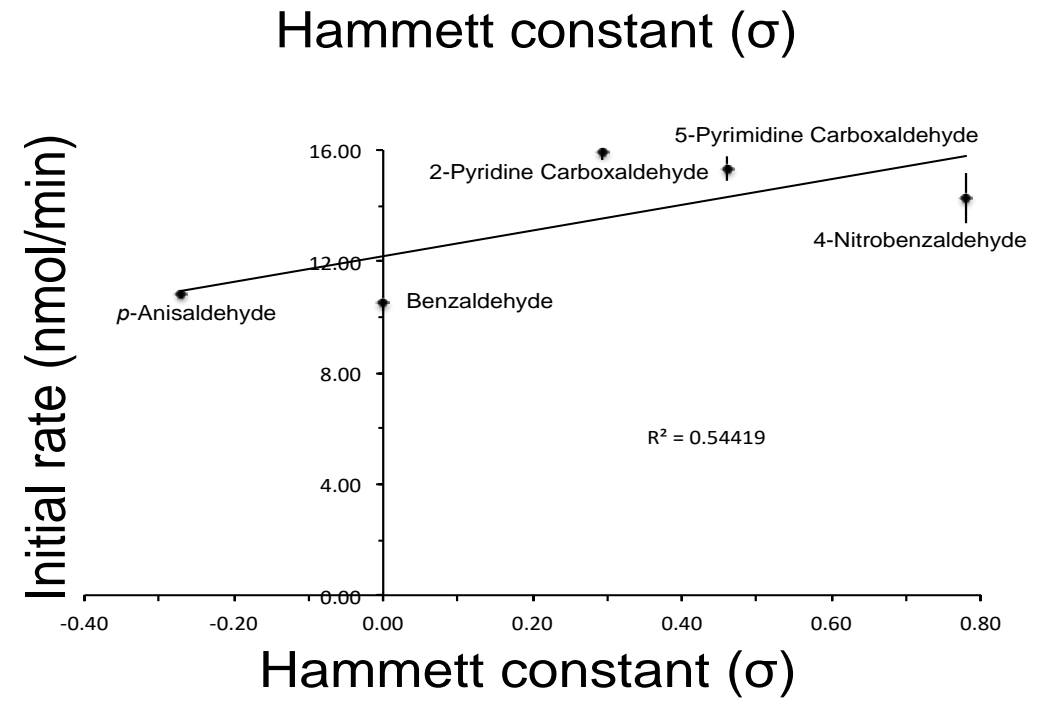

C)

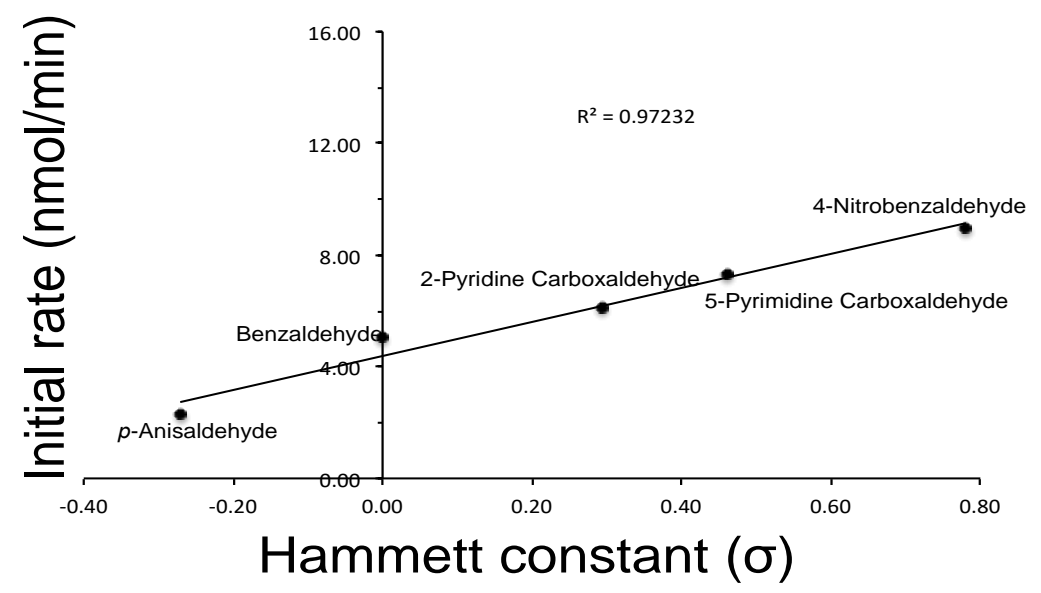

Jain et al. 
Figure 5: (a) Measured values of $\log \left(\mathrm{K} / \mathrm{K}_{\mathrm{o}}\right)$ vs. known Hammett constant values. Hammett constants for 2-pyridine carboxaldehyde and 5-pyrimidine carboxaldehyde were extrapolated using the equation in the figure. (b) Correlation plot of initial enzymatic rate vs. Hammett constant for all five substrates in the presence of NADH cofactor. (c) BNAH correlation plot of initial enzymatic rate vs. Hammett constants. Interestingly, reactions conducted in the presence of BNAH cofactor show an excellent correlation $\left(\mathrm{R}^{2}=0.972\right)$ between the inductive effect exerted by the substrates and the observed reaction rates (Figure 5c). Our enzyme kinetic assays show that 4nitrobenzaldehyde has the highest reactivity $(9.0 \pm 0.2 \mathrm{nmoles} / \mathrm{min})$ amongst the five substrates tested and the reaction rate correlates well with its large Hammett constant value of 0.78 . Similarly, p-anisaldehyde, which is electron donating in nature due to the presence of the $-\mathrm{OCH}_{3}$ group, shows the lowest reactivity $(2.3 \pm 0.1 \mathrm{nmoles} / \mathrm{min})$ and the smallest Hammett constant value (-0.27).

These results suggest that the reduction reactions catalyzed by the LADH enzyme in the presence of BNAH cofactor are primarily governed by the inductive effect exerted by the substrate molecules even though steric factors such as the presence of BNAH and substrate in a particular orientation within the active site of the enzyme are important. Previous work has shown that there is some plasticity in the alcohol dehydrogenase active site during reactions with substrates that vary in structure. [31] Furthermore, BNAH (although similar to NADH in its hydride donor reaction) is structurally distinct from NADH and likely binds weakly to the enzyme active site. In the absence of a lockand-key induced fit mechanism that is observed in a naturally occurring active site of the LADH enzyme with bound $\mathrm{NADH}$, the electronic environment of the substrates is the primary driver of the reaction rates in the presence of BNAH. 


\section{Comparison with zinc model complexes}

Recently, we prepared a series of tridentate SNS zinc(II) pincer complexes that model the zinc(II) active site of the LADH enzyme. [6, 23] The tridentate pincer SNS ligand precursors incorporate bis-thione substituted based imidazole and triazole moieties. The nitrogen donor atom comes from a nitrogen atom in a pyridine ring. [25] We wanted to determine whether the conclusions reached in our LADH trials with different substrates could be extended to a synthetic model enzyme complex. Synthetic model complexes have enormous potential especially in industrial applications because higher product yields can be achieved at elevated temperature and pressure which necessitates the use of synthetic model enzyme active sites as well as a cofactor mimetic like BNAH. For example, Schrock and co-workers have reduced dinitrogen to ammonia using a molybdenum catalyst. [32] The tridentate ligands used in some of these systems were relatively rigid as the pyridine and the imidazoles were directly bound to each other. By using the starting material 2,6-(dibromomethyl) pyridine, we introduced a methylene linker into the pincer ligand, thereby allowing us to examine the effect of ligand flexibility on substrate binding. We modified the electronic environment imparted by our ligand set through the use of imidazole- and triazole-based precursors. [33,34] In order to understand the presence and sterics of ancillary alkyl groups on the ability of these model systems to reduce aldehydes, the ligands were prepared with imidazolyl or triazolyl rings having $\mathrm{R}$ groups of various sizes as shown in Figure 6. 


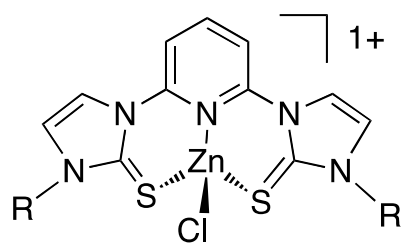

1a-c

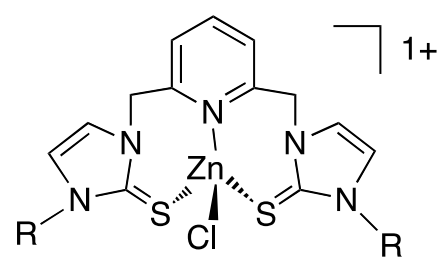

2a-c

$\mathrm{R}=\mathbf{a}=\mathbb{P r} ; \mathbf{b}=$ neopentyl; $\mathbf{c}=N$-butyl

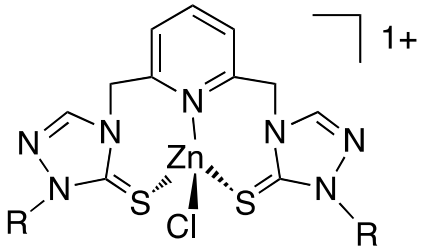

3a-c

Figure 6: Zinc-based SNS model complexes previously prepared by Miecznikowski et al. $[6,23,25]$

Based on the data we previously published, the choice of the alkyl group is important as zinc complex 3c (Figure 6) gave the highest percent conversion for the conversion of 4-nitrobenzaldehyde to 4-nitrobenzyl alcohol in the presence of BNAH in refluxing $\mathrm{CDCl}_{3}$. [23].

In order to correlate the biochemical assay results and the cyclic voltammetry results with our model system reactivity data, we screened zinc complex 3c for activity through the reduction of a variety of aldehydes in the presence of BNAH (eq. 1 and 2).
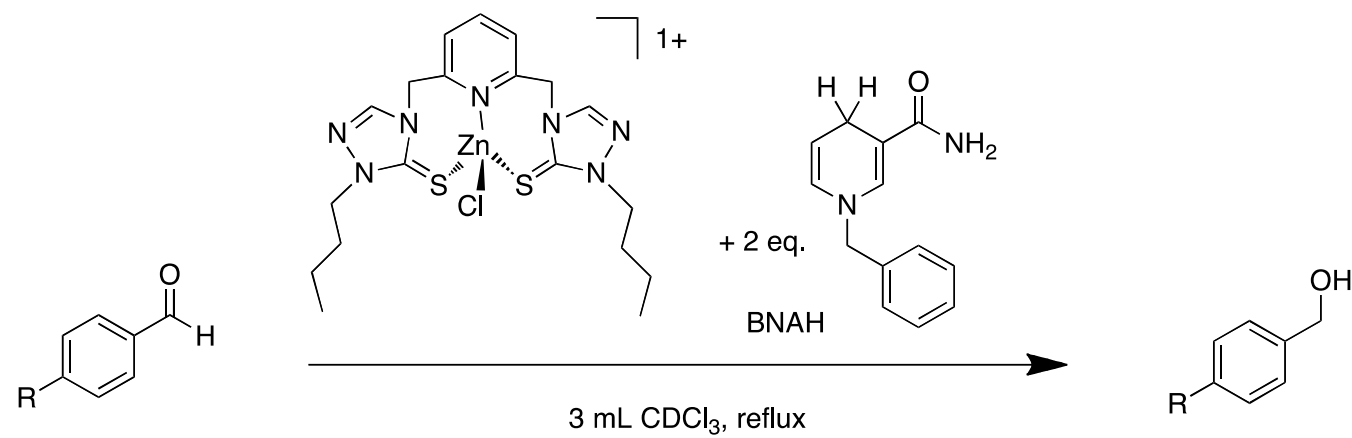

(eq. 1)

$\mathrm{R}=\mathrm{NO}_{2}$ (4-nitrobenzaldehyde); $\mathrm{H}$ (benzaldehyde); OMe ( $\mathrm{p}$-anisaldehyde);<smiles>O=Cc1ccccn1</smiles>

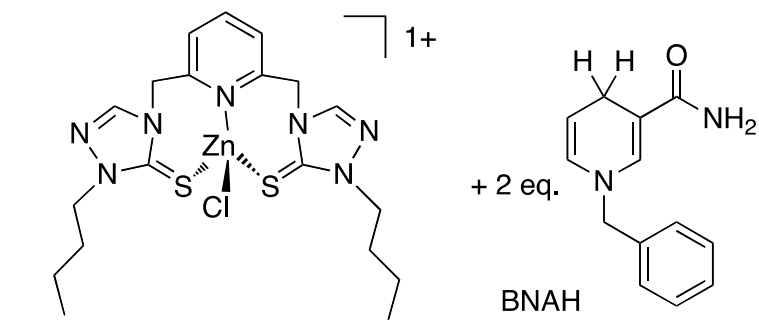

$3 \mathrm{~mL} \mathrm{CDCl}$, reflux

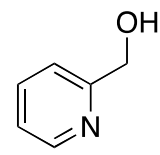

(eq. 2)

Jain et al. 
Table 1 illustrates the reactivity data for the most active zinc complex, 3c, as well as for $\mathrm{ZnCl}_{2}$ (eq. 1 and 2). For all reactivity experimentation, $0.1 \mathrm{mmol}$ of aldehyde, 0.1 mmol zinc precursor or $0.2 \mathrm{mmol}$ of $\mathrm{ZnCl}_{2}$, and $0.2 \mathrm{mmol} \mathrm{BNAH}$ were used. Product formation was detected by ${ }^{1} \mathrm{H}$ NMR by comparison with authentic material.

For the conversion of 4-nitrobenzaldehyde to 4-nitrobenzyl alcohol, ${ }^{1} \mathrm{H}$ NMR was used to follow the disappearance of the aldehyde proton ( $\delta 10.2 \mathrm{ppm})$ and the shifting of the aromatic $\mathrm{C}-\mathrm{H}$ protons in the alcohol product $(\delta 8.24 \mathrm{ppm})$. For the reduction of 2pyridine carboxaldehyde, ${ }^{1} \mathrm{H}$ NMR spectroscopy was used to follow the disappearance of the aldehyde proton $(\delta 10.1 \mathrm{ppm})$ and the appearance of the aromatic $\mathrm{C}-\mathrm{H}$ protons in the alcohol product $(\delta 8.0 \mathrm{ppm})$. For the conversion of benzaldehyde to benzyl alcohol, ${ }^{1} \mathrm{H}$ NMR spectroscopy was used to follow the disappearance of the aldehyde proton $(\delta 10.0$ ppm) and the appearance of the methylene protons in the alcohol product ( $\delta 4.7 \mathrm{ppm})$. Finally, for the reduction of p-anisaldehyde, ${ }^{1} \mathrm{H}$ NMR spectroscopy was used to follow the disappearance of the aldehyde proton $(\delta 9.9 \mathrm{ppm})$ and the appearance of the methylene protons in the alcohol product $(\delta 4.8 \mathrm{ppm})$. For all of the substrates, the aromatic proton resonances of the $\mathrm{C}-\mathrm{H}$ protons in the alcohol product were spectroscopically distinct from the other products or the starting material's resonances and no overlap of ${ }^{1} \mathrm{H}$ NMR resonances was observed (Figure S2, Supplementary Information).

As shown in Table 1, the SNS zinc(II) complex enhances the rate of the reaction for the conversion of 4-nitrobenzaldehyde to 4-nitrobenzyl alcohol when compared to $\mathrm{ZnCl}_{2}$. In no case was there any indication of reduction of nitro substituents. Use of the SNS zinc(II) complex results in quantitative conversion of 2-pyridine carboxaldehyde to 
pyridin-2-ylmethanol. 2-pyridine carboxaldehyde may be a good substrate for reduction by the zinc complex since there may be faster hydrogen transfer between the co-factor and the substrate, upon coordination to the zinc active site. Mechanistically, others have proposed a hydrogen atom transfer between the cofactor and the substrate upon coordination to the zinc active site based upon a previously reported mechanism for LADH enzyme offered by Makowska-Grzyska and co-workers. [35] A proposed mechanism for the reduction of aldehydes by LADH is given below in figure 7 .

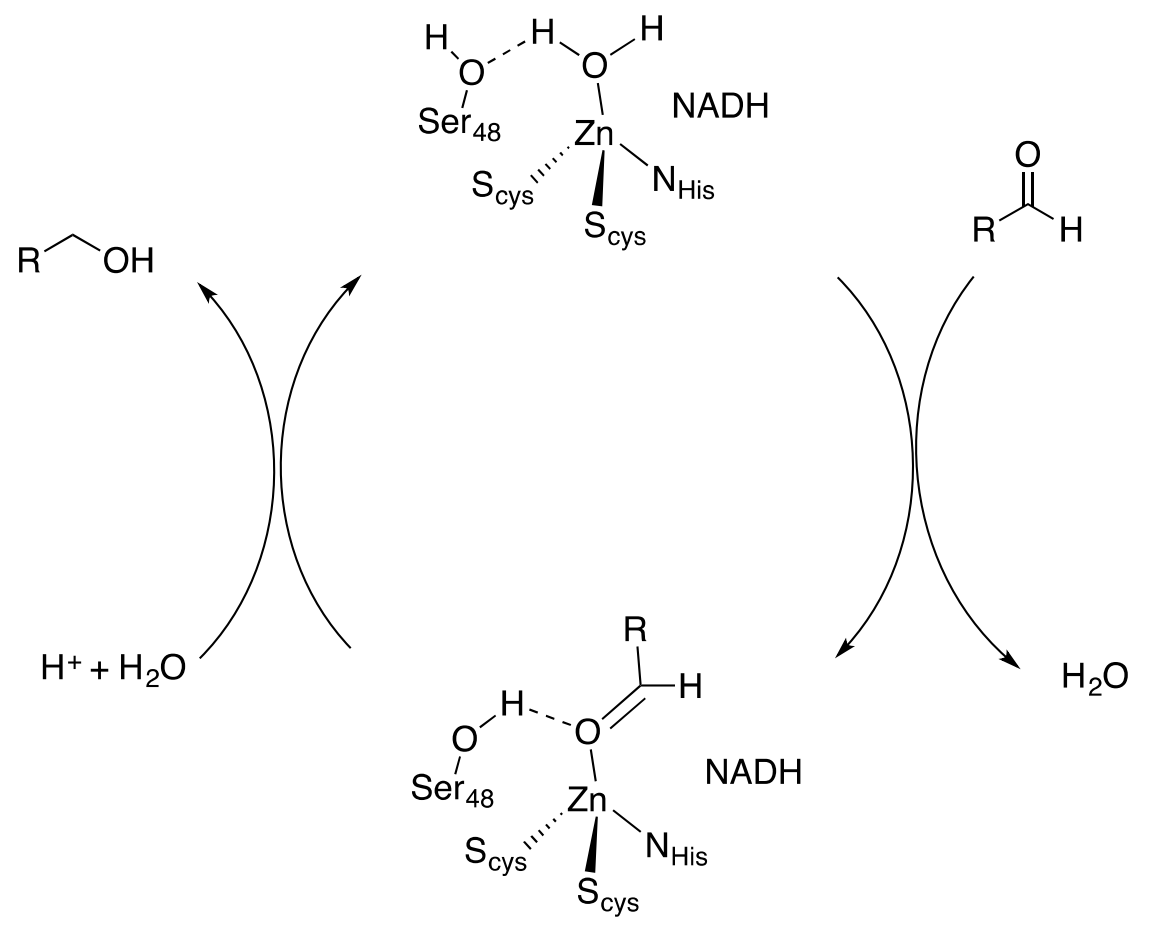

Figure 7: Plausible mechanism for the reduction of aldehydes by LADH 
Table 1. Stoichiometric reactivity data for the reduction of aldehydes by a SNS zinc(II) pincer complex.

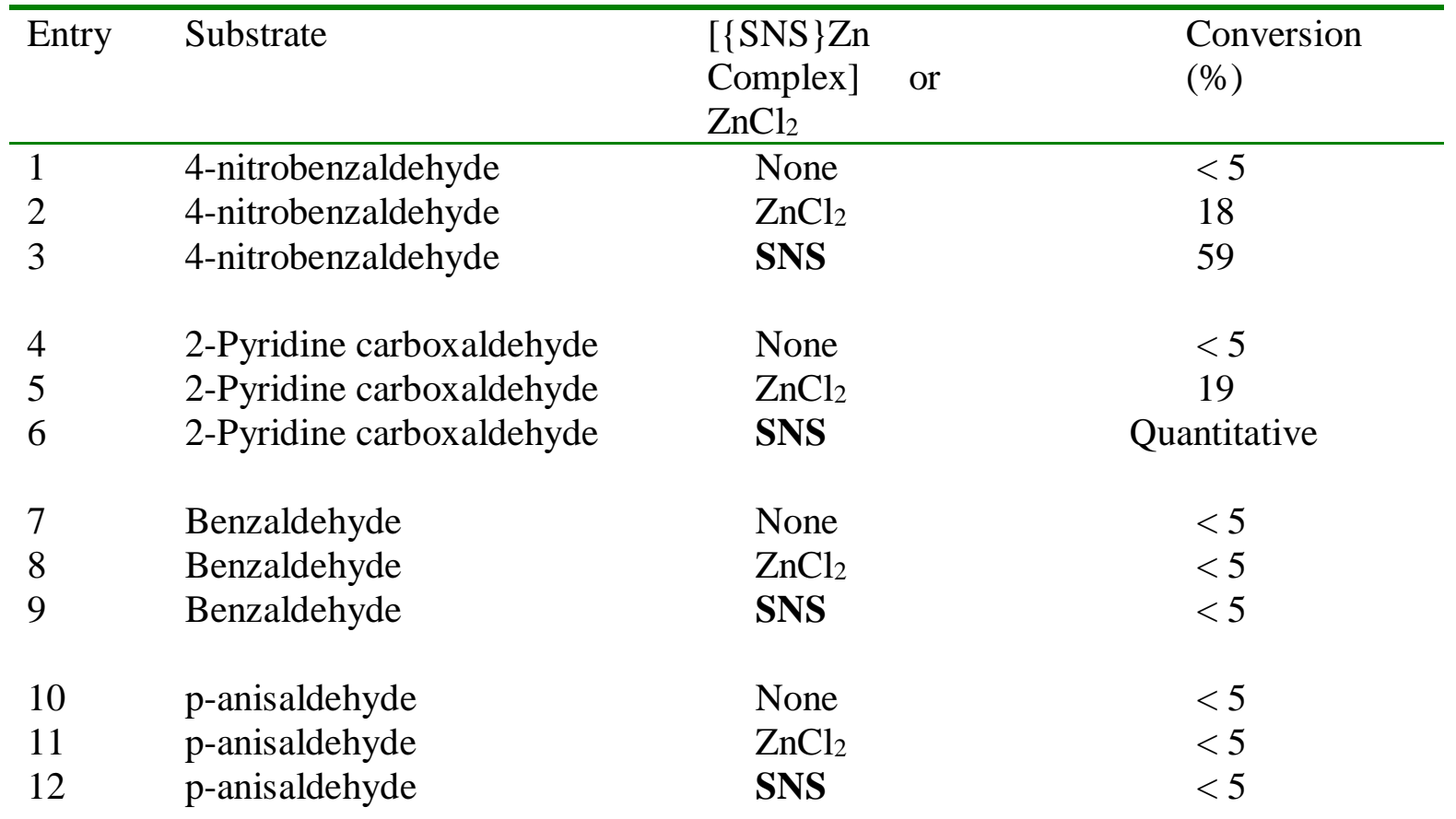

Conditions: $0.1 \mathrm{mmol}$ aldehyde, $0.2 \mathrm{mmol}$ BNAH, $0.1 \mathrm{mmol}$ SNS Zn Complex or 0.2 $\mathrm{mmol} \mathrm{ZnCl}_{2}$, and $3 \mathrm{~mL} \mathrm{CDCl}$. All reactions were run for $20 \mathrm{hrs}$.

The more electron rich aldehydes (Table 1 , entries 7 -12) were not reduced when the aldehydes were reacted with BNAH and the zinc complex. For these examples, the substrate itself may poison the zinc complex by coordinating to the zinc complex during the reaction. For the substrates where reduction was observed, the alcohol product may inhibit the reaction. As the alcohol is formed, it may coordinate to the zinc metal center as the reaction progresses, and thereby hinder the reaction.

Entries 2 and 5 in Table 1 indicate that $\mathrm{ZnCl}_{2}$ reacts stoichiometrically with electron-withdrawing aldehydes such as 4-nitrobenzaldehyde or 2-pyridine carboxaldehyde to yield the alcohol product to a small extent (ca. 18-19\% conversion). 
We therefore propose that $\mathrm{Zn}^{2+}$ acts as a Lewis acid catalyst in the reaction where $\mathrm{ZnCl}_{2}$ is utilized for these substrates. Very little, if any, reduction was seen when $\mathrm{ZnCl}_{2}$ was reacted stoichiometrically with the other aldehyde substrates listed in table 1 (entries 8 , and 11) and shown in equation 1. Results obtained with our zinc model complex 3c parallel those obtained with natural enzyme because electron withdrawn substrates, 4nitrobenzaldehyde and 2-pyridine carboxaldehyde, show substantially higher reactivity in both the studies. Furthermore electron rich aldehydes, benzaldehyde and p-anisaldehyde show minimal reactivity, which is also in agreement with our results in both the enzymatic and model complex systems.

\section{Conclusions}

Under physiological conditions, BNAH was used as a biomimetic for the natural cofactor NADH in reduction reactions catalyzed by liver alcohol dehydrogenase enzyme. In order to better understand the changes in reaction rates in the presence of NADH and BNAH, we conducted a substrate study and found that natural cofactor NADH had a poor correlation $\left(\mathrm{R}^{2}=0.544\right)$ between the inductive effect exerted by the substrates and their corresponding enzymatic rate, while reactions conducted in the presence of BNAH cofactor showed an excellent correlation $\left(\mathrm{R}^{2}=0.972\right)$ between the inductive effect exerted by the substrates and the observed reaction rates. These results demonstrate that catalysis in the presence of $\mathrm{NADH}$ is largely dependent upon steric factors, whereas catalysis in the presence of BNAH is primarily influenced by the substrate's inductive effect. We also compared the catalytic activity of LADH enzyme with a synthetic model enzyme complex, tridentate SNS zinc(II) pincer compound that models the zinc(II) active 
site of the LADH enzyme in terms of chemical structure and redox properties. Current work in our laboratory is focused on the modifications of BNAH at the 1 and 6 positions of the nicotinamide ring with electron donating and electron withdrawing functional groups. Our aim is to determine whether the inductive effect argument and its subsequent effect on reaction rates can be extended to cofactors and not just substrates alone.

\section{Acknowledgements}

This work is supported by Research Corporation grant \# 21054 (SSJ) and a Dreyfus Corporation Undergraduate Research and Lectureship award (SSJ). Generous support is also acknowledged from The Bard Summer Research Institute (SSJ, JS, XT), The Fairfield University Science Institute (JRM, CEV, EEB, and LCK), Bard College (SSJ) and Fairfield University (JRM) start-up funding, Fairfield University Research Grants (JRM), and the Fairfield University Chemistry Department Summer Research Kuck Fund (CEV, EEB, and LCK). 


\section{References}

[1] H. Eklund, C.I. Brändén, J. Biol. Chem. 254 (1979) 3458-3461.

[2] Ramaswamy, D.H. Park, B.V. Plapp, Biochemistry. 38 (1999) 13951-13959.

[3] K.K. Kannan, B. Notstrand, K. Fridborg, S. Loevgren, A. Ohlsson, M. Petef. Proc Natl Acad Sci USA. 72 (1975) 51-55.

[4] H.C. Lo, R.H. Fish, Angew Chem Int Ed. 41 (2002) 478-481.

[5] R. Meijers, R.J. Morris, H.W. Adolph, A. Merli, V.S. Lamzin, E.S. CedergrenZeppezauer. J. Biol. Chem. 276 (2001) 9316-9321.

[6] J.R. Miecznikowski, W. Lo, M.A. Lynn, S. Jain, L.C. Keilich, L.C.; N.F. Kloczko, B.E. O’Loughlin, A.P. DiMarzio, K.M. Foley, G.P. Lisi, D.J. Kwiecien, E.E. Butrick, E. Powers, R. Al-Abbasee, R. Inorg Chim Acta, 387 (2012) 25-36.

[7] J. Lutz, F. Hollmann, T.V. Ho, A Schnyder, R.H. Fish, A. Schmid. J Organomet Chem. 689 (2004) 4783-4790.

[8] K.K. Kannan, B. Nostrand, B. K. Fridborg, S. Lovgren, A. Ohlsson, M Petef, Proc. Natl. Acad. Sci, USA, 72 (1975) 51.

[9] J.A. Ibers, R.H. Holm, Science. 209 (1980) 223-235.

[10] L. Cronin, P.H. Walton, Chem Commun. 20 (2003) 2638.

[11] A. Dołęga, A. Pladzyk, K. Baranowska, J. Jezierska, Inorg. Chim. Acta. 362 (2009) 5085-5096.

[12] A. Dołęga. Wiadomosci Chemiczne, 64 (2010) 389-411.

[13] A. Kropidowski, J. Chojnacki, B. Becker. J Inorg Biochem, 101 (2007) 578-584.

[14] F. Effenberger, J. Roos, C. Kobier. Angew. Chem Int. Ed, 41 (2002) 1876-1879.

[15] O. Seneque, O. Reinaud, M. Giorgi. Chem Commun (2011) 984-985.

[16] L. M. Berreau, M.M. Makowska-Grzska, A.M. Arif. Inorg Chem, 40 (2001) 22122213.

[17] C. Kimblin, B.M. Bridgewater, D.G. Churchill, G. Parkin, Chem. Commun, (1999) 2301-2302.

[18] C. Kimblin, T. Hascall, G. Parkin, Inorg. Chem, 36 (1997), 5680-5681. 
[19] S.C. Shoner, K.J. Humphreys, D. Barnhart, J.A. Kovacs, Inorg Chem, 34 (1995) 5933-5934.

[20] D.T. Corwin, Jr., R. Fikar, S.A. Koch, Inorg Chem, 26 (1987), 3079-3080.

[21] A.K.H. MacGibbon, S.C. Koerber, K. Pease, M.F. Dunn, Biochemistry 26 (1987) 3058-3067.

[22] R.G. Khalifah, Inorg Chim Acta, 32 (1979), L53-L55.

[23] J.R. Miecznikowski, W. Lo, M.A. Lynn, B.E. O’Loughlin, A.P. DiMarzio, A M. Martinez, L. Lampe, K.M. Foley, L.C. Keilich, G.P. Lisi, D.J. Kwiecien, C.M. Pires, W.J. Kelly, N.F. Kloczko, K.N. Morio. Inorg Chim Acta, 2011, 376, 515524.

[24] a) R. Walz, H. Vahrenkamp, Inorg. Chim. Acta 314 (2001) 58-62. (b) Y.H. Zhang, H. Vahrenkamp, Inorg. Chim. Acta, 351(2003) 201-206.

[25] J.R. Miecznikowski, J.P. Jasinski, M.A. Lynn, S. Jain, E.E. Butrick, A.R. Drozdoski, K.A. Archer, J.T. Panarra. Inorg Chim Acta, 394 (2013) 310-321.

[26] L.P. Hammett, J Am. Chem Soc. 59 (1937) 96-103

[27] C.H. Blomquist, Acta Chem Scand. 20 (1966)1747-1757.

[28] R.F. Boyer, Concepts in Biochemistry, first ed., Brooks/Cole Pub Co, pp.147-162.

[29] W.K. Seok, T.J. Meyer, Inorg Chem. 44 (2005) 3931-3941.

[30] W.P. Jencks, Catalysis in Chemistry and Enzymology, McGraw-Hill Book Company, New York, 2000.

[31] S. Ramaswamy, H. Eklund, B.V. Plapp, Biochemistry. 33 (1994) 5230-5237.

[32] D.V. Yandulov, R.R. Schrock, Science 2003, 301, 76-78.

[33] J.R. Miecznikowski, R.H. Crabtree, Organomet 23 (2004) 629-631.

[34] J.R. Miecznikowski, R.H. Crabtree, Polyhedron. 23 (2004) 2857-2872.

[35] M.M. Makowska-Grzyska, P.C. Jeppson, R.A. Allred, A.M. Arif, L.M. Berreau. Inorg Chem. 41 (2002) 4872-4887. 


\section{Graphical Abstract}

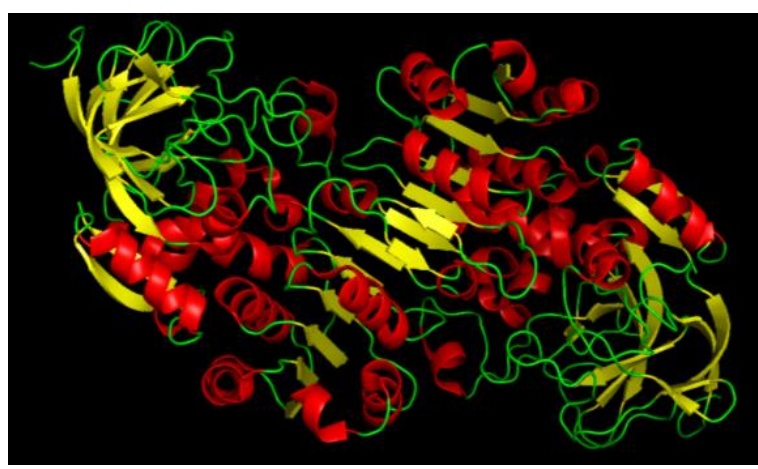

Liver alcohol dehydrogenase enzyme

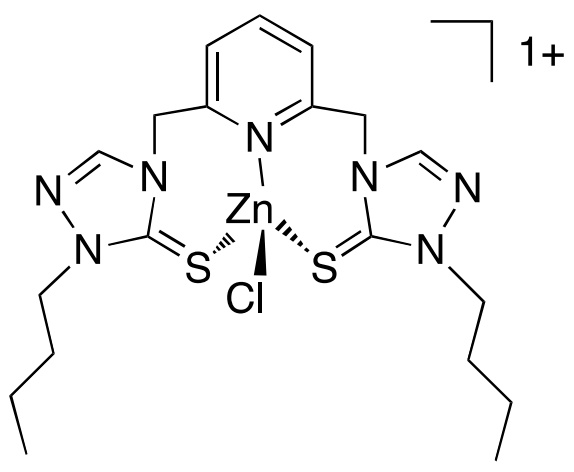

vs. Model Zinc Active Site Complex

\section{Synopsis for Graphical Abstract (50 words)}

We have compared the catalytic activity of liver alcohol dehydrogenase enzyme to a synthetic model active site zinc complex. Substrates that vary in their ability to donate or withdraw electron density from the reaction center were used to differentiate between geometric and electronic factors that govern the observed reaction rates. 


\section{Highlights}

- Liver alcohol dehydrogenase enzyme can catalyze reduction reactions in the presence of BNAH (a biomimetic of NADH cofactor).

- Catalytic activity of the enzyme was compared to a synthetic model zinc active site complex.

- Substrates were varied to determine the role of steric and electronic factors.

- In the presence of NADH, steric factors govern reaction rates whereas in the presence of $\mathrm{BNAH}$, the electronic environment of the substrate determines the reaction rates. 


\section{Supplementary Information File}

\section{Investigation of liver alcohol dehydrogenase catalysis using an NADH biomimetic and comparison with a synthetic zinc model complex}

James R. Sunderland ${ }^{1}$, Xingjian Tao ${ }^{1}$, Elizabeth E. Butrick ${ }^{2}$, Lauren C. Keilich ${ }^{2}$, Christine E. Villa ${ }^{2}$, John R. Miecznikowski ${ }^{2 *}$, and Swapan S. Jain ${ }^{1 *}$

${ }^{1}$ Department of Chemistry, Bard College, 30 Campus Road, Annandale-on-Hudson, NY 12504, USA

${ }^{2}$ Department of Chemistry and Biochemistry, Fairfield University, 1073 North Benson Road, Fairfield, CT 06824, USA

- Corresponding Author: Tel: +1845752 2354. Fax: +1 845752 2339. Email: sjain@ bard.edu

- * Tel: 1-203-254-4000 x 2125. Fax +1 203-254-4034. Email: jmiecznikowski@fairfield.edu. 
Table S1: Enzymatic reduction of substrates in the presence of NADH and BNAH (biomimetic of $\mathrm{NADH}$ ). Initial rate data and product formation over time are presented below.

\begin{tabular}{|l|l|l|}
\hline Substrate (cofactor) & $\begin{array}{l}\text { Initial rates }(\text { nmoles } \\
\text { aldehyde converted to } \\
\text { alcohol/min) }\end{array}$ & $\begin{array}{l}\text { Conversion over time (20 } \\
\text { min w/ NADH and 60 min } \\
\text { w/ BNAH) }\end{array}$ \\
\hline p-Anisaldehyde $(\mathrm{NADH})$ & $10.80( \pm 0.16) \mathrm{nmoles} / \mathrm{min}$ & $111.4( \pm 1.68) \mathrm{nmoles}$ \\
\hline p-Anisaldehyde $(\mathrm{BNAH})$ & $2.27( \pm 0.07) \mathrm{nmoles} / \mathrm{min}$ & $105.47( \pm 3.20) \mathrm{nmoles}$ \\
\hline Benzaldehyde $(\mathrm{NADH})$ & $10.49( \pm 0.26) \mathrm{nmoles} / \mathrm{min}$ & $182.1( \pm 4.47) \mathrm{nmoles}$ \\
\hline Benzaldehyde $(\mathrm{BNAH})$ & $5.04( \pm 0.27) \mathrm{nmoles} / \mathrm{min}$ & $157.6( \pm 4.25) \mathrm{nmoles}$ \\
\hline $\begin{array}{l}\text { 4-Nitrobenzaldehyde } \\
(\mathrm{NADH})\end{array}$ & $14.26( \pm 0.90) \mathrm{nmoles} / \mathrm{min}$ & $238.8( \pm 15.0) \mathrm{nmoles}$ \\
\hline $\begin{array}{l}\text { 4-Nitrobenzaldehyde } \\
(\mathrm{BNAH})\end{array}$ & $8.96( \pm 0.23) \mathrm{nmoles} / \mathrm{min}$ & $181.9( \pm 4.72) \mathrm{nmoles}$ \\
\hline $\begin{array}{l}\text { 5-Pyrimidine } \\
\text { Carboxaldehyde }(\mathrm{NADH})\end{array}$ & $15.33( \pm 0.43) \mathrm{nmoles} / \mathrm{min}$ & $198.0( \pm 6.37) \mathrm{nmoles}$ \\
\hline $\begin{array}{l}\text { 5-Pyrimidine } \\
\text { Carboxaldehyde }(\mathrm{BNAH})\end{array}$ & $7.28( \pm 0.18) \mathrm{nmoles} / \mathrm{min}$ & $227.6( \pm 5.60) \mathrm{nmoles}$ \\
\hline $\begin{array}{l}\text { 2-Pyridine Carboxaldehyde } \\
(\mathrm{NADH})\end{array}$ & $15.89( \pm 0.24) \mathrm{nmoles} / \mathrm{min}$ & $215.8( \pm 3.25) \mathrm{nmoles}$ \\
\hline $\begin{array}{l}\text { 2-Pyridine Carboxaldehyde } \\
(\mathrm{NADH})\end{array}$ & $6.08( \pm 0.09) \mathrm{nmoles} / \mathrm{min}$ & $261.1( \pm 3.94) \mathrm{nmoles}$ \\
\hline
\end{tabular}


Figure S2a: ${ }^{1} \mathrm{H}-\mathrm{NMR}$ of 2-pyridine carboxaldehyde (starting material) at $0 \mathrm{hrs}$.

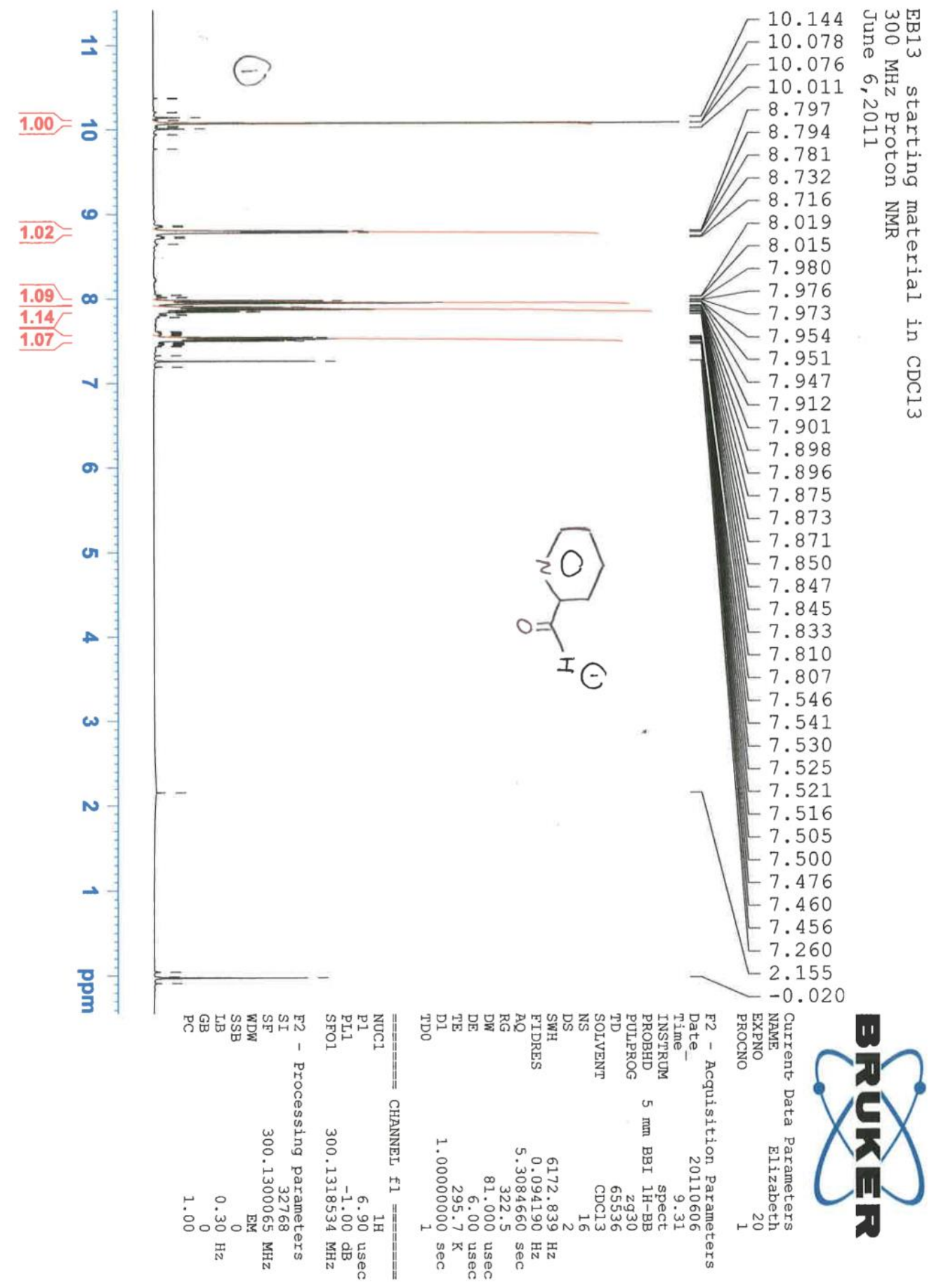


Figure S2b: ${ }^{1} \mathrm{H}-\mathrm{NMR}$ of the alcohol product after reaction (20 hrs) with BNAH and zinc complex 3c. Disappearance of the aldehyde peak at $10.1 \mathrm{ppm}$ and the appearance of $\mathrm{C}-\mathrm{H}$ aromatic proton resonances of the alcohol product at $\sim 8.0 \mathrm{ppm}$ indicate reaction progress.

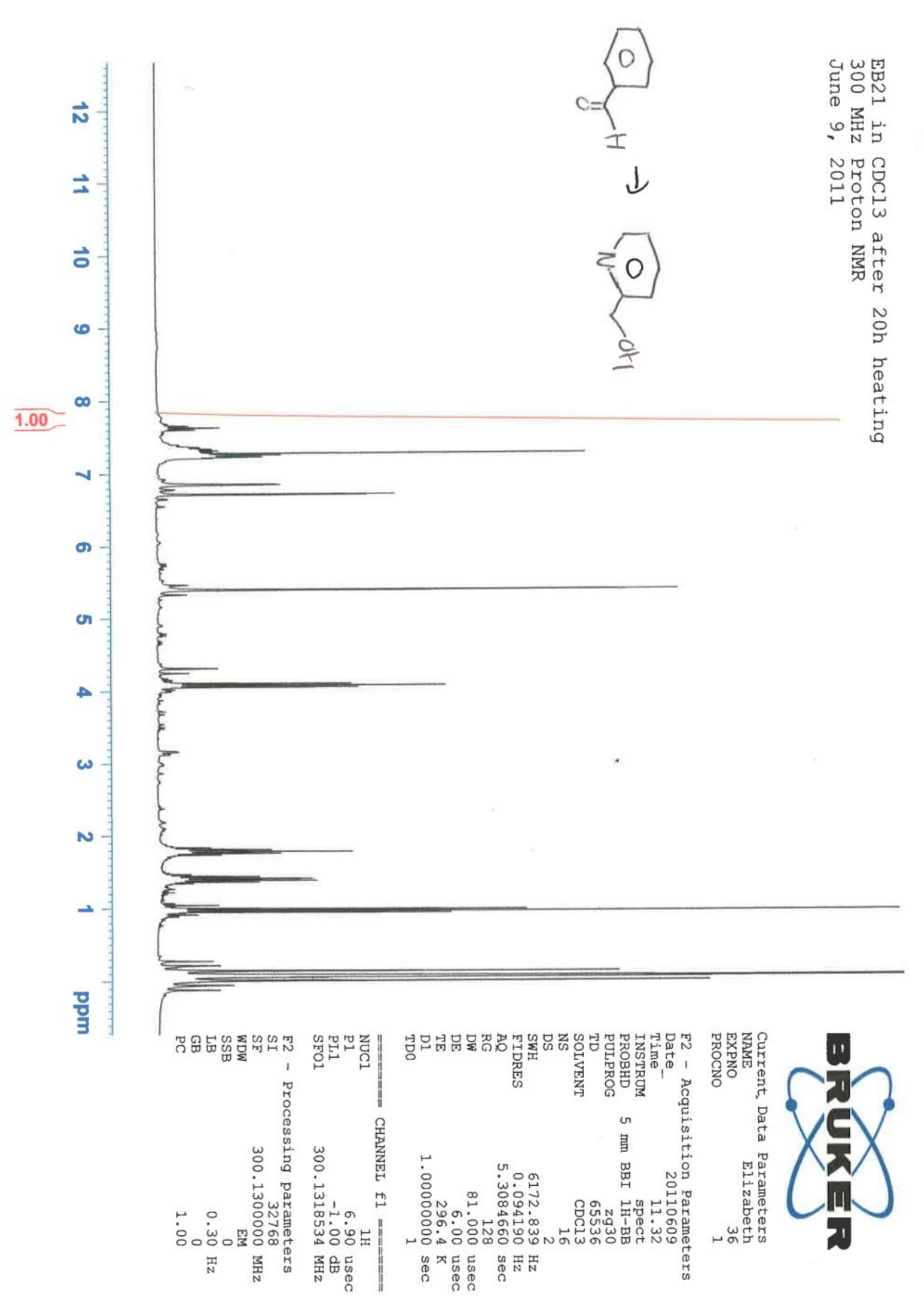


Figure S3a: Cyclic Voltammogram of p-anisaldehyde.

\section{Cyclic Voltammetry Profile of $p$-Anisaldehyde}

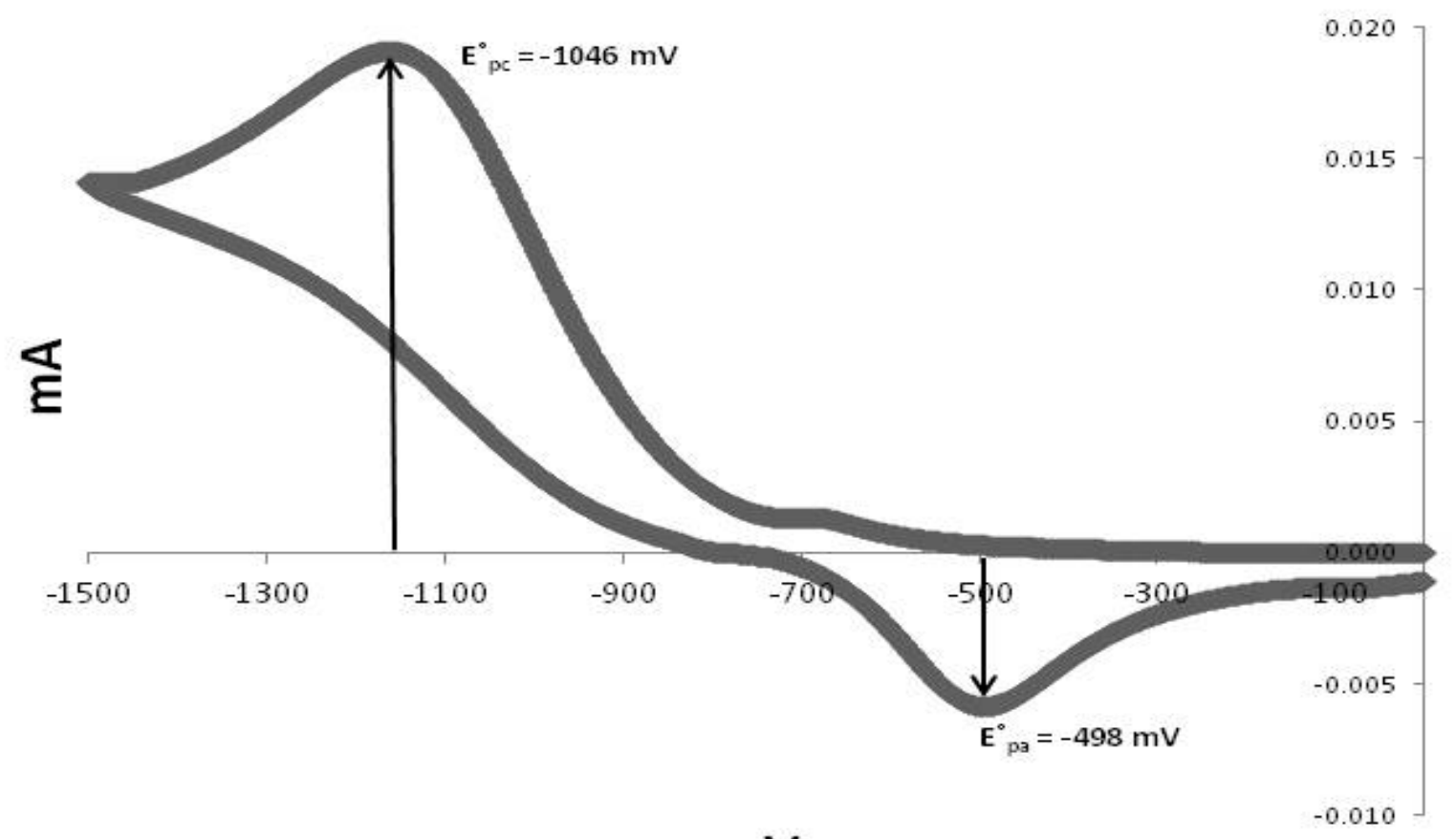

$\mathrm{mV}$ 
Figure S3b: Cyclic Voltammogram of benzaldehyde.

\section{Cyclic Voltammetry Profile of Benzaldehyde}

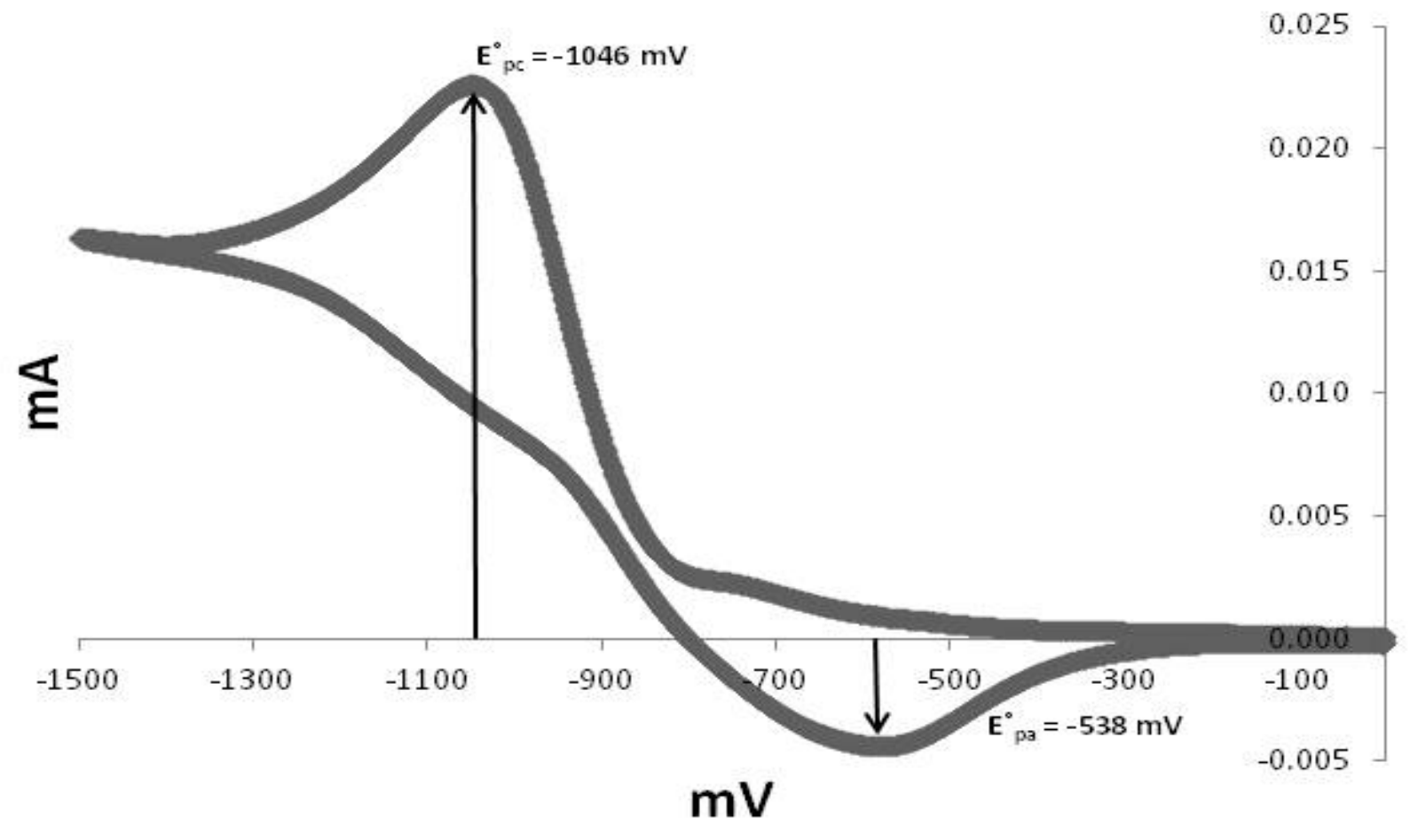


Figure S3c: Cyclic Voltammogram of p-nitrobenzaldehyde.

\section{Cyclic Voltammetry Profile of $p$-Nitrobenzaldehyde}

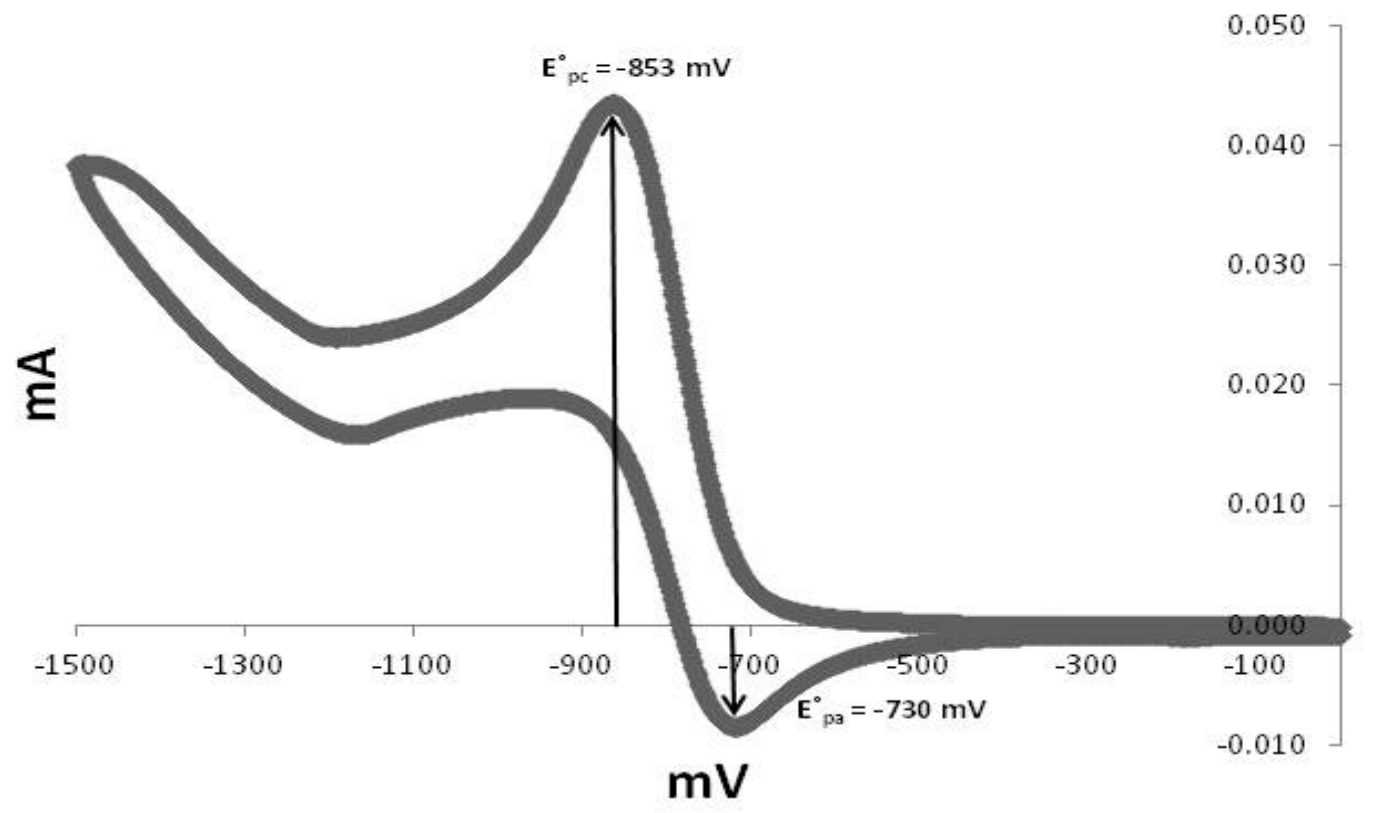


Figure S3d: Cyclic Voltammogram of 2-pyridine carboxaldehyde.

\section{Cyclic Voltammetry Profile of 2-Pyridinecarboxaldehyde}

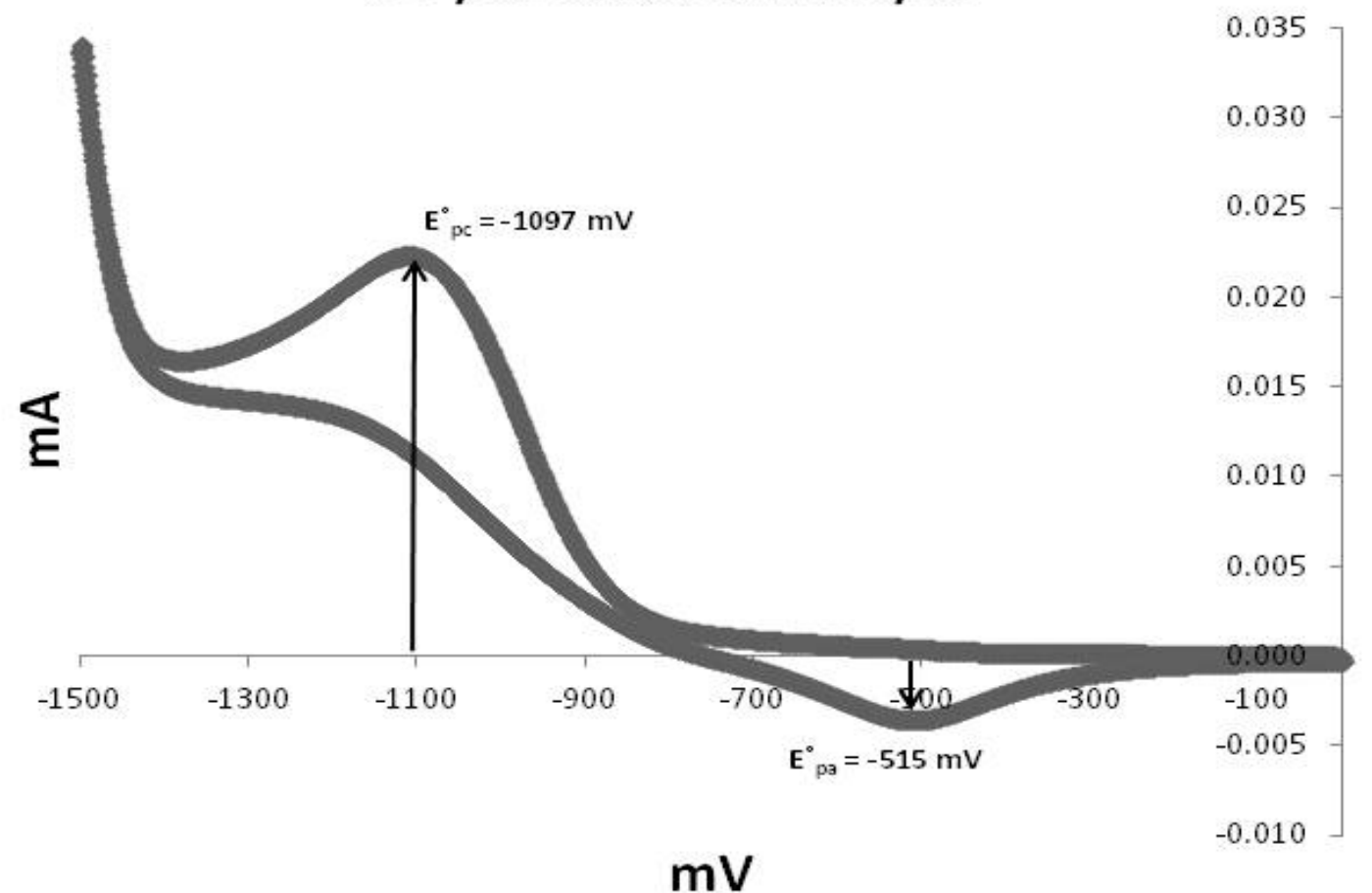

$\mathrm{mV}$ 
Figure S3e: Cyclic Voltammogram of 5-pyrimidine carboxaldehyde.

\section{Cyclic Voltammetry Profile of 5-Pyrimidinecarboxaldehyde}

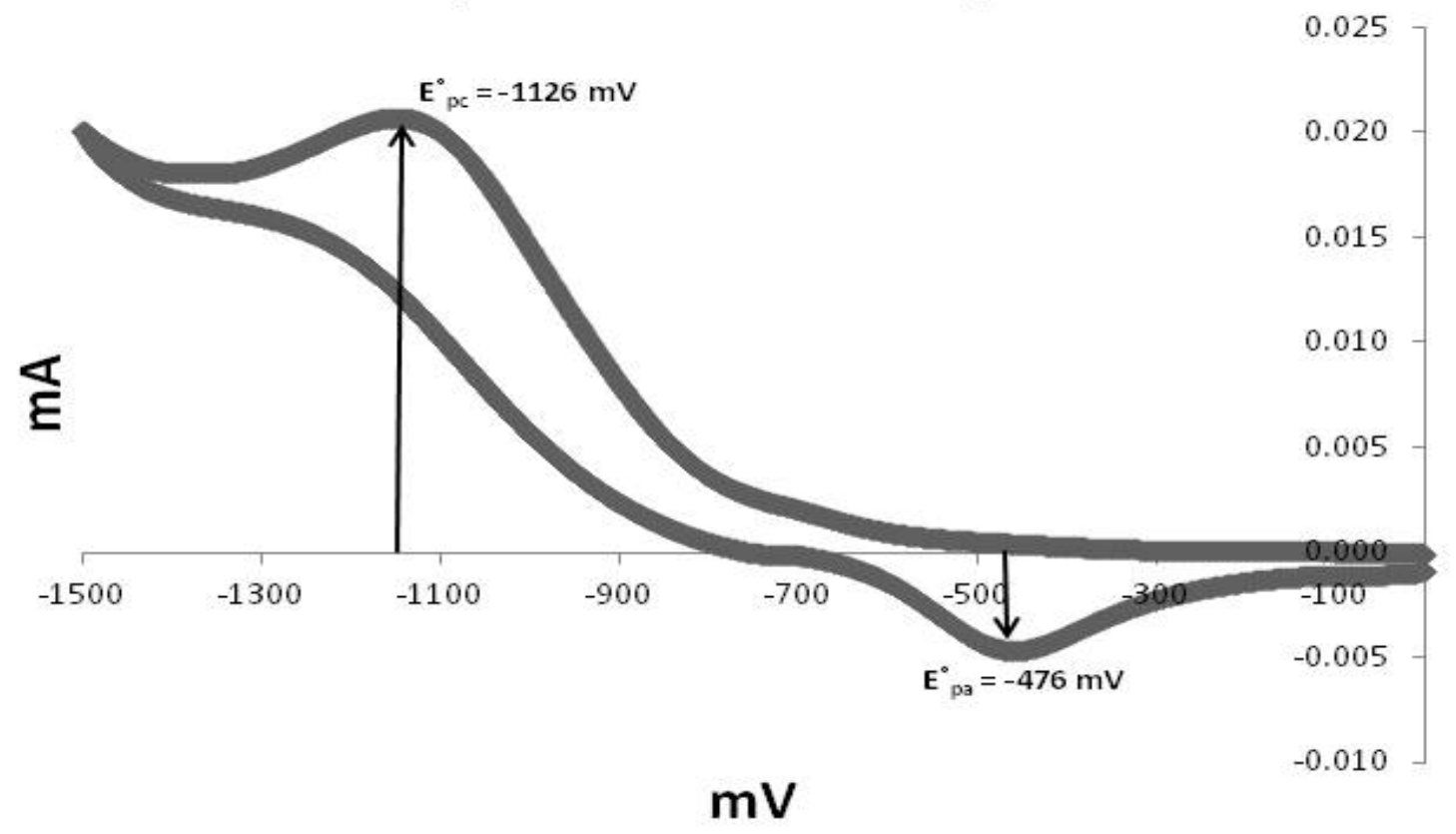




\section{Table S2 and calculation of unknown Hammet Constants from cyclic voltammograms}

Cyclic voltammetry (CV) was carried out using gold electrodes and the scans were run from $0 \mathrm{mV}$ down to the $-1500 \mathrm{mV}$ and back to $0 \mathrm{mV}$. Calculated data for all five substrates is shown in Table $\mathrm{S} 2$ below. From the cyclic voltammograms, we used the $E^{\circ} \mathrm{pc}$ value which is where the reduction occurred and $E^{\circ} \mathrm{pa}$ where the oxidation occurred, and calculated $E^{\circ} 1 / 2$ by taking an average. Then we plotted $E^{\circ} 1 / 2$ into Nernst equation to calculate $\log K$.

Sample calculation for Benzaldehyde is shown below. The CV plot for Benzaldehyde is shown as Fig. S3b.

$E^{\circ} 1 / 2=\left(E^{\circ} \mathrm{pa}+E^{\circ} \mathrm{pa}\right) / 2=(-1046+(-583)) / 2=815 \mathrm{mV}$ or $0.815 \mathrm{~V}$

Using Nernst equation, we calculate a value of log $\mathrm{K}$

$$
\log (K)=\frac{E^{\circ} 1 / 2}{(R T / n F)}=-31.719
$$

*Benzaldehyde was used as the reference compound to which all other aldehydes were compared. For Benzaldehyde,

$$
\log \left(K / K^{\circ}\right)=\log \mathrm{K}-\log K^{\circ}=(-31.719)-(-31.719)=0
$$

For $\mathrm{p}$-Anisaldehyde, we find the $\log \left(K / K^{\circ}\right)$ value as follows:

$$
\log \left(K / K^{\circ}\right)=\log \mathrm{K}-\log K^{\circ}=-32.050-(-31.719)=-0.331
$$

Table S2. Cyclic voltammetry data of five substrates.

\begin{tabular}{|l|c|c|c|c|c|c|}
\hline \multicolumn{1}{|c|}{ Substrate } & $\mathrm{E}^{\circ} \mathrm{pc}(\mathrm{mV})$ & $\mathrm{E} \mathrm{pa}(\mathrm{mV})$ & $\mathrm{E}^{\circ} 1 / 2(\mathrm{~V})$ & $\log (\mathrm{K})$ & $\log \left(\mathrm{K} / \mathrm{K}^{\circ}\right)$ & $\sigma$ \\
\hline Benzaldehyde & -1046 & -583 & -0.815 & -31.719 & 0 & -0.27 \\
\hline p-Anisaldhyde & -1148 & -498 & -0.823 & -32.050 & -0.331 & 0 \\
\hline p-Nitrobenzaldhyde & -853 & -730 & -0.792 & -30.824 & 0.896 & 0.78 \\
\hline 2-Pyridinecarboxaldehyde & -1097 & -515 & -0.806 & -31.388 & 0.331 & $0.29 * *$ \\
\hline 5-Pyrimidinecarboxaldehyde & -1126 & -476 & -0.801 & -31.194 & 0.526 & $0.46^{* *}$ \\
\hline
\end{tabular}

* Benzaldehyde is the reference substrate since it is neither electron-withdrawn or electron-donated.

Jain et al. 
** Calculation of Hammett Constants $(\sigma)$

Figure 5a in the manuscript was made where $\log \left(K / K^{\circ}\right)$ were plotted on the $y$-axis vs. literature Hammett constants on the $\mathrm{x}$-axis for benzaldehyde, anisaldehyde, and $\mathrm{p}$ nitrobenzaldehyde. The following equation was obtained.

$Y=1.1641 x-0.0096$

Hammett equation: $\log \left(K / K^{\circ}\right)=$

where $\rho$ which is $1.1641 . \log \left(K / K^{\circ}\right)$ for 2-pyridine carboxaldehyde and 2-pyrimidine carboxaldehyde were used to calculate their Hammett constant value using equations above. 
Figure S4a: Control study of LADH enzyme and NADH without substrate.

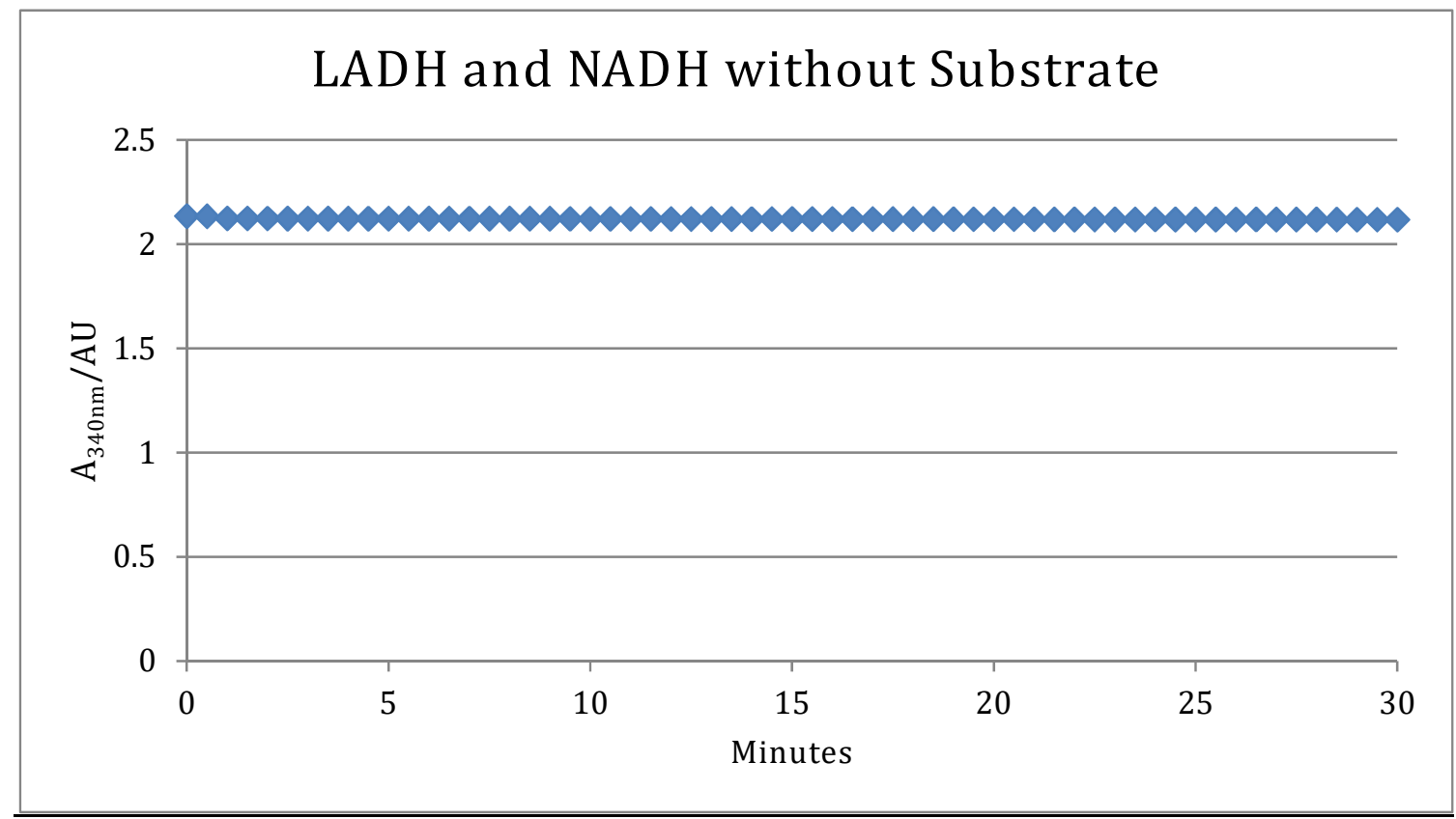

$\Delta \mathrm{A}_{340} / \mathrm{min}=-0.00056$ (not significant) 
Figure S4b: Control study of benzaldhyde substrate and NADH without LADH enzyme.

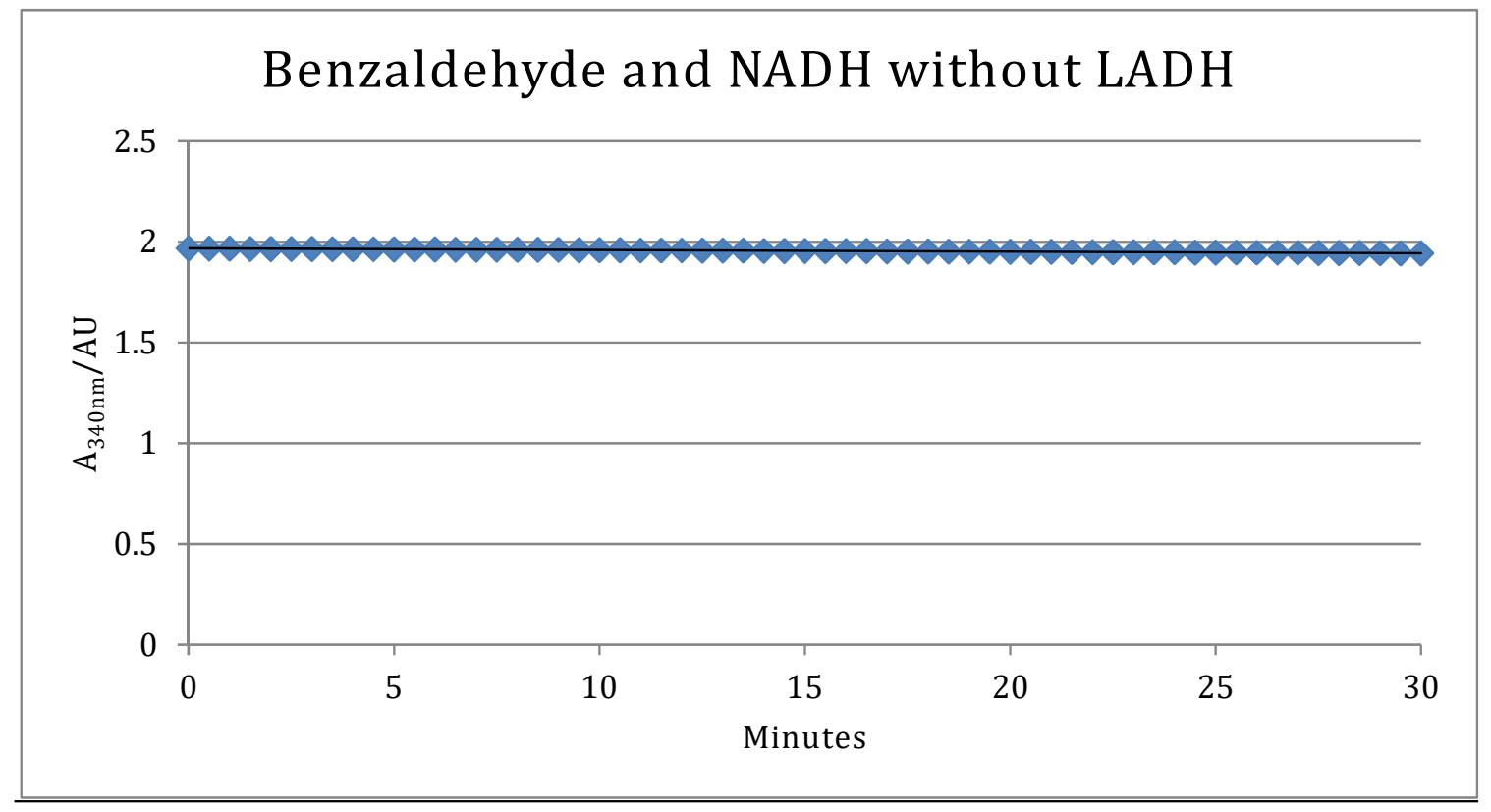

$\Delta \mathrm{A}_{340} / \mathrm{min}=-0.0008$ (not significant) 
Figure S4c: Control study of LADH enzyme and BNAH without substrate.

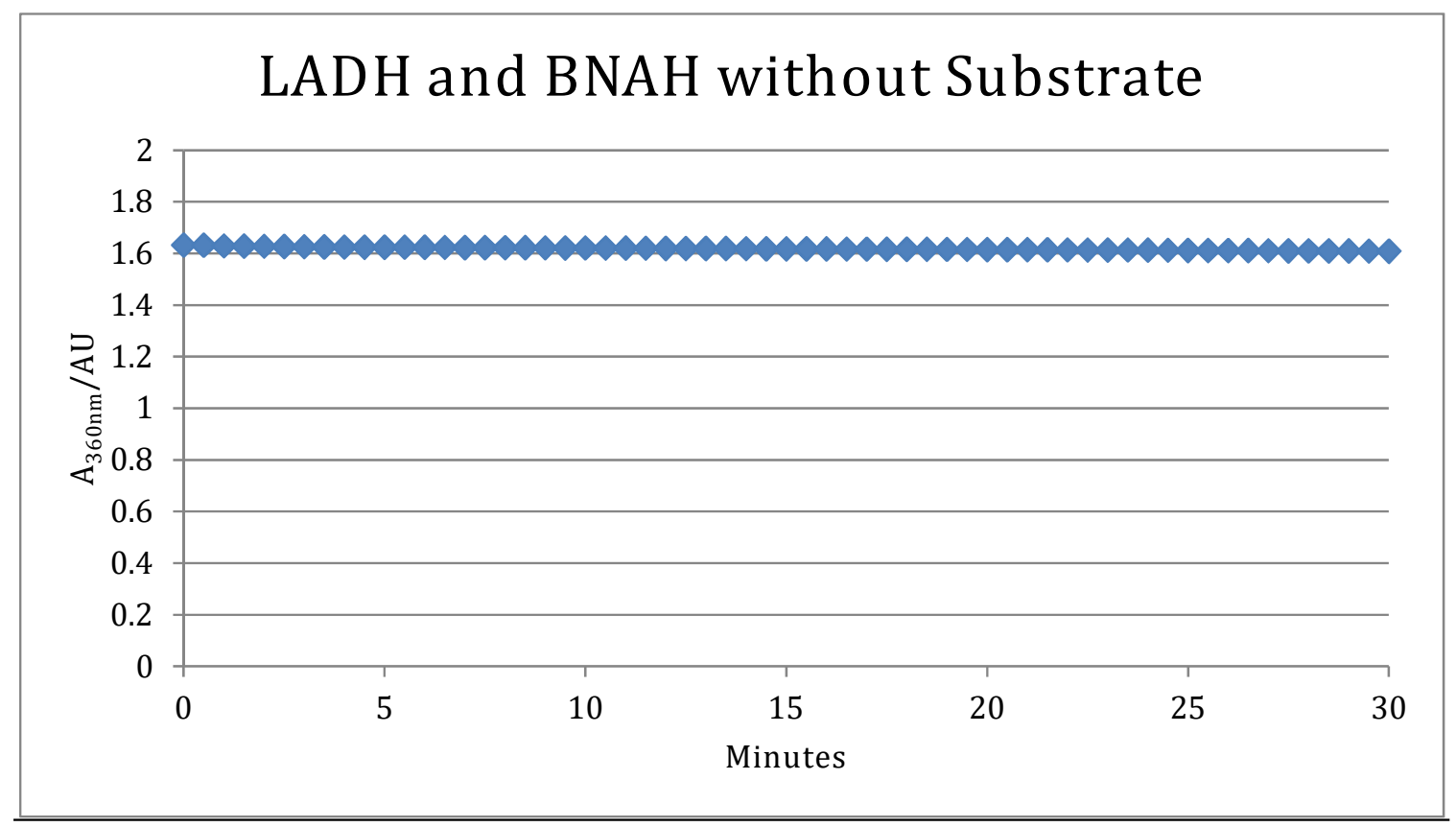

$\Delta \mathrm{A}_{360} / \min =-0.0 .00078$ (not significant) 
Figure S4d: Control study of benzaldehyde substrate and BNAH without LADH enzyme.

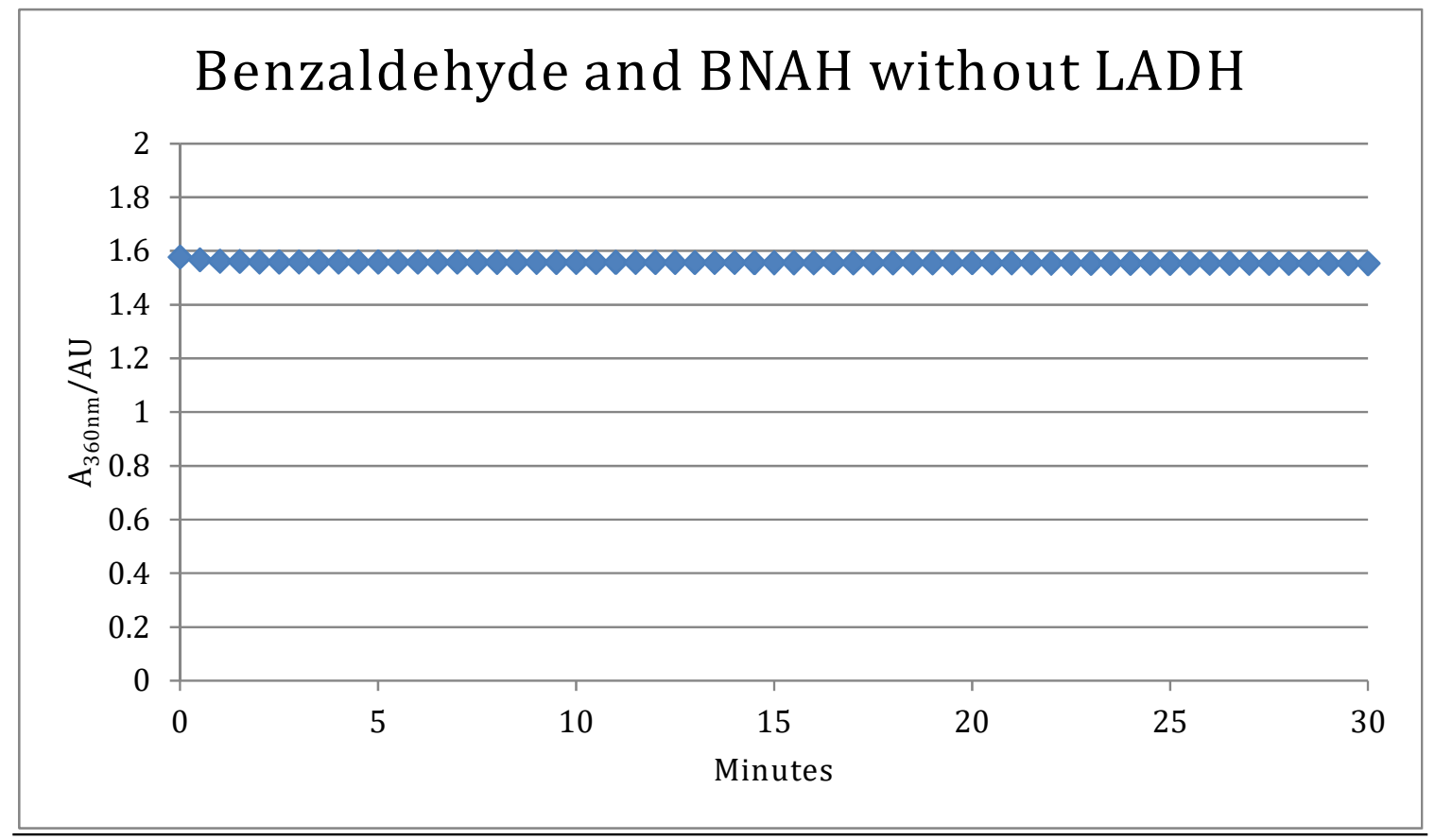

$\Delta \mathrm{A}_{360} / \mathrm{min}=-0.0008$ (not significant) 